\title{
GEOLOGIA E GÊNESE DAS MINERALIZAÇÕES ASSOCIADAS AO MACIÇO ITAOCA, VALE DO RIBEIRA, SP e PR
}

\author{
IVAN SERGIO DE CAVALCANTI MELLO * \& JORGE SILVA BETTENCOURT **
}

\begin{abstract}
GEOLOGY AND GENESIS OF MINERALIZATIONS RELATED TO THE ITAOCA MASSIF, RIBEIRA VALLEY, SP AND $P R$ The Itaoca granitoid massif covers an area above $200 \mathrm{~km}$ and is believed to be part of the Ribeira Folded Belt being confined to the Ribeira Valley, wich occupies the south-southest part of the State of São Paulo, southern Brazil.

The batholith is intrusive and circunscript in character and also emplaced into metasedimentary rocks of the Lajeado Subgroup, partially refered to the Açungui Group. The stratigraphy of the Lajeado Subgroup is revised and partially correlated to the Água Clara Formation, positioned below this unit.

The massif consists mainly of high potassium calc-alkaline monzonitic granitoids, a composite of multiple granitoid igneous units considered to be cogenetic injections derived from a deep seated crust. Field relations, petrography, mineralogy, chemical compositions, isotopic signatures and related metallogeny suggest a similarity of Itaoca with I type granitoid, magnetite plutons. The truncated discordant contact relationships, aureoles, internal facies distribuition and the physico-chemical skarn formation characteristics indicate that the granites are mesozonal to epizonal in character and were emplaced at a depth in the range of 6 to $7 \mathrm{~km}$.

The batholith is a late component of Andinotype subduction related magmatic arc and is also considered to be syn to late-kinematic in relation to the Neoproterozoic Açungui Basin deformation episode.

The ore deposits are directly associated with roof pendant skarn bodies, located in the central part of the massif, and include: wollastonite $\left(\mathrm{CaSiO}_{3}\right)$ and scheelite-powellite $\left[\mathrm{Ca}(\mathrm{W}, \mathrm{Mo}) \mathrm{O}_{4}\right]$ wich were formed by magma interaction (thermal metamorphism) with surronding roof pendant cabonate rock. The wollastonite was generated by decarbonation reaction of the country rock marbles by contact metamorphism. The mineralized bodies are classic W-Mo-Cu bearing, calcic contact skarns. The skarns and associated mineralization were formed during two major stages, metassomatic and hydrothermal, under peak contact metamorphism conditions of about $600{ }^{\circ} \mathrm{C}$ and $2 \mathrm{kbar}$. Besides wollastonite and scheelite-powellite mineralization there is an overprint of a sulphide assemblage containing pyrite, pyrrhotyte, arsenopyrite, molibdenite, sphalerite, and chalcopyrite wich might be related to slightly falling temperatures accompanied by reduced conditions and hydration of the skarn mineral assemblages. Malaquite, azurite and gold are also present being final products generated at low temperatures conditions. The oxidation state of the magma, the amount of initial water, the depth of emplacement of the batholith, the types of mineralization, the $\delta^{13} \mathrm{C}$ and $\delta^{18} \mathrm{O}$ skarn isotopic signatures suggest a magmatic origin for the tungsten mineralization.

Correlation of roof pendant and metasedimentary contact rock of Itaoca pluton as well as regional metamorphic rock units, can be used to constrain the origin of the contact skarn rocks. The Agua Clara Formation marble horizons might favor the generation of stratabound skarn bodies whereas the source and relative abundance of metasomatic fluids might reflect and be subordinate to the nature and evolution of the granitoid intrusion.
\end{abstract}

Keywords: Ribeira Belt, Itaoca Massif, W-Mo-Cu Skarn, Wollastonite, Sheelite-Powellite Mineralization.

RESUMO O maciço granitóide Itaoca possui área superior a $200 \mathrm{~km}^{2}$ e integra os terrenos pré-cambrianos do Cinturão Ribeira que afloram no sul-sudeste de São Paulo e nordeste do Paraná (Vale do Ribeira), como parte das faixas de dobramento do Sudeste do Brasil.

As encaixantes do batólito são rochas metassedimentares doJSubgrupo Lajeado (parcialmente equivalente ao Grupo Açungui), cuja estratigrafia é revisada, e parcialmente correlacionada com a Formação Água Clara, considerada basal à unidade Lajeado.

Foram reconhecidas e mapeadas no maciço, intrusivo e circunscrito, fácies e associações de fácies granitóides calcioalcalinas monzoníticas de alto potássio, a magnetita, do tipo I.

A natureza do batólito e de suas encaixantes, a relação de contato das ígneas com rochas metassedimentares, a distribuição das fácies intrusivas no maciço e os parâmetros físico-químicos de formação dos depósitos minerais da área permitem considerá-lo posicionado entre a epizona e mesozona crustais, entre 6 a $7 \mathrm{~km}$ de profundidade, e formado por várias injeções cogenéticas, por balloning, a partir de magma precursor gerado na base da crosta.

A sistemática $\mathrm{Rb} / \mathrm{Sr}$, aplicada em rochas totais, atribui ao batólito Itaoca idade isocrônica de $626 \mathrm{Ma}$. Dentro da evolução geológica do Vale do Ribeira, o maciço pode ser considerado tardio ao desenvolvimento de arco magmático do tipo andino, e sin a tardi-tectônico em relação a episódio de deformação da bacia Açungui, no final do Neoproterozóico (Brasiliano).

No batólito há ocorrências minerais diversas, dentre as quais se destacam as de wollastonita (CaSiOs) e scheelita-powellita [Ca(W,Mo)O4], em escarnitos formados por metamorfismo térmico de contato da intrusão sobre mármores de pendentes do teto, no centro do batólito. A wollastonita foi gerada por processos de descarbonatação das matrizes marmóreas dos escarnitos, durante o metamorfismo de contato. Quanto aos depósitos metálicos, os corpos mineralizados do maciço Itaoca são representantes clássicos dos W-Mo-Cu escarnitos de contato presentes em diversas partes do mundo. Estes corpos e as mineralizações associadas formaram-se em estágios metassomáticos e hidrotermais, a partir dos $600{ }^{\circ} \mathrm{C}$ e pressão em torno de 2 kbar. À mineralização de wollastonita e scheelita-powellita se superpõem sulfetos diversos (pirita, pirrotita, arsenopirita, molibdenita, esfalerita, calcopirita, bornita), minerais supérgenos de cobre (malaquita e azurita), e ouro, gerados em temperaturas sucessivamente mais baixas. A partir da linhagem granitóide do Itaoca, a tipologia dos depósitos e as assinaturas isotópicas de estrôncio, carbono e oxigênio dos escarnitos, sugere-se uma origem magmática para o conteúdo metálico do estágio metassomático destes corpos.

Com base em correlações entre as matrizes marmóreas dos escarnitos e os litotipos associados dos pendentes do teto do batólito Itaoca, as rochas metassedimentares da borda do maciço e as unidades rochosas regionais, formula-se modelo para a geração de escarnitos de contato no Vale do Ribeira, que seriam corpos stratabound, associados aos horizontes de mármore da Formação Agua Clara, basal ao Subgrupo Lajeado, enquanto que os principais conteúdos metálicos desses corpos metassomáticos estariam subordinados à natureza das intrusivas granitóides envolvidas na formação dos escarnitos.

Palavras-chave: Cinturão Ribeira, Maciço Itaoca, W-Mo-Cu Escarnito, Wollastonite, Sheelite-Powellite.

INTRODUÇÃO O Maciço Itaoca localiza-se na divisa dos Estados de São Paulo e Paraná, no vale do rio Ribeira de Iguape (Fig. 1). Possui natureza granitóide e é uma intrusão integrante dos terrenos pré-cambrianos daquela faixa.

$\mathrm{O}$ macico foi abordado em sínteses sobre a geologia regional (i.e. Melchere/a/. 1973, Morgental et al. 1975, JICA 1981, 1982, 1983), caracterização e classificação de corpos granitóides paulistas (Hasui et ai. 1978, Vlach et al. 1990, Janasi \& Ulbrich 1991), em estudos dos granitóides do Vale do Ribeira (Gomes et al. 1975a,b, Wernick \& Gomes 1974, 1977, Wernick 1979), e em estudos metalogenéticos sobre a região (Chiodi Filho et al. 1989). Considerações sobre a petrologia do batólito foram feitas por Landim et al. (1975).
Durante os anos 80 e início dos 90, o maciço foi estudado pelo Instituto de Pesquisas Tecnológicas do Estado de São Paulo-IPT, quando foram descobertos e estudados os principais recursos minerais da área. Desses trabalhos resultou um grande número de dados, reunidos em relatórios técnicos e resumidos em Mello et al. (1981), Mello \& Silva (1984), Mello et al. (1985), Mello \& Bettencourt (1992) e Tassinari \& Mello (1994). Com a exploração mineral, foram identificados escarnitos mineralizados, formados a partir de mármores de pendentes do teto da intrusão. As mineralizações mais importantes são de wollastonita $\left(\mathrm{CaSiO}_{3}\right)$ e scheelita-powellita $\left[\mathrm{Ca}(\mathrm{W}, \mathrm{Mo}) \mathrm{O}_{4}\right]$. Os conhecimentos acumulados com a prospecção mineral ensejaram teses sobre a petrogênese dos escarnitos de Itaoca (Ens 1990) e sobre a 
geologia e gênese dos depósitos minerais associados ao maciço (Mello 1995), esta última resumida neste trabalho.

CONTEXTO GEOLÓGICO O Cinturão de Dobramentos Ribeira (Hasui et al. 1975), na divisa entre São Paulo e Paraná, é constituído por unidades arqueanas a neoproterozóicas que compreendem núcleos de alto grau metamórfico, faixas milonito-gináissicas, seqüências

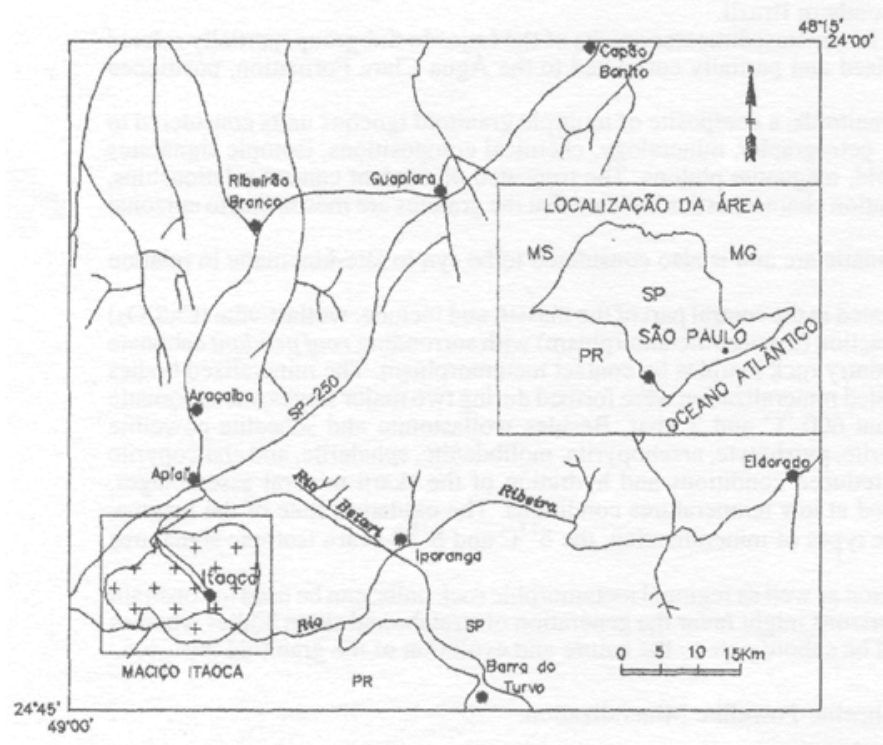

Figura l-Localização do maciço Itaoca. metavulcanossedimentares, alguns corpos metabásicos e diversos maciços granitóides. Estas unidades estão estruturadas de modo complexo e sua evolução é ainda controversa.

GEOLOGIA DO MACIÇO O batólito Itaoca está em contato direto com quartzitos, xistos e mármores do Subgrupo Lajeado, de Campanha et al. (1986, 1987), unidade em parte equivalente ao Grupo Açungui de Hasui et al. (1984), e admitida pelos primeiros autores como do Mesoproterozóico (Fig. 2).

Os contatos do maciço com as encaixantes são discordantes a parcialmente concordantes, condições em que as unidades da borda do batólito mostram-se vergadas ou basculadas. Tais relações de contato, aliadas ao metamorfismo termal sobre as unidades regionais e pendentes do teto do maciço, configuram a intrusão como circunscrita, nos termos de Raguin (1976).

O mapeamento das fácies do maciço permitiu reconhecer três domínios principais, respectivamente de granitóides cinzentos, róseos e miloníticos, respectivamente designados como unidades Itaoca, Saltinho e Milonítica (Fig. 3 e Tabela 1). Na Figura 3, a representação das unidades encaixantes ao maciço Itaoca foi parcialmente modificada de MMAJ/JICA (1981, 1982, 1983), Campanha et al (1988) e Campanha (1991). Já a descrição das unidades litoestratigráficas encaixantes constantes da Tabela 1 baseia-se em MMAJ/JICA (1982, 1983), e Campanha era/. (1988, 1991).

O maciço abrange, pelo menos, seis fácies intrusivas mais comuns (Cinza 1 e 2, Rósea 1, 2, 3 e 4), e ainda uma fácies (Cinza 3) e uma associacão de fácies (Róseas 5), ambas balizadas por falhas ou zonas de cisalhamento, interpretadas como produtos autometassomáticos resultantes de alterações tardi a pós-magmáticas. Além dessas, ocorre uma associação de tectonofácies (Miloníticas) resultante de deformação das fácies intrusivas. As características petrográficas, modais e químicas das fácies identificadas estão resumidas nas Tabelas 2 a 4, e na Figura 4.

A Unidade Itaoca perfaz cerca de $70 \%$ da área do batólito, e ocorre nas partes central, norte e leste da intrusão. É constituída pelas fácies

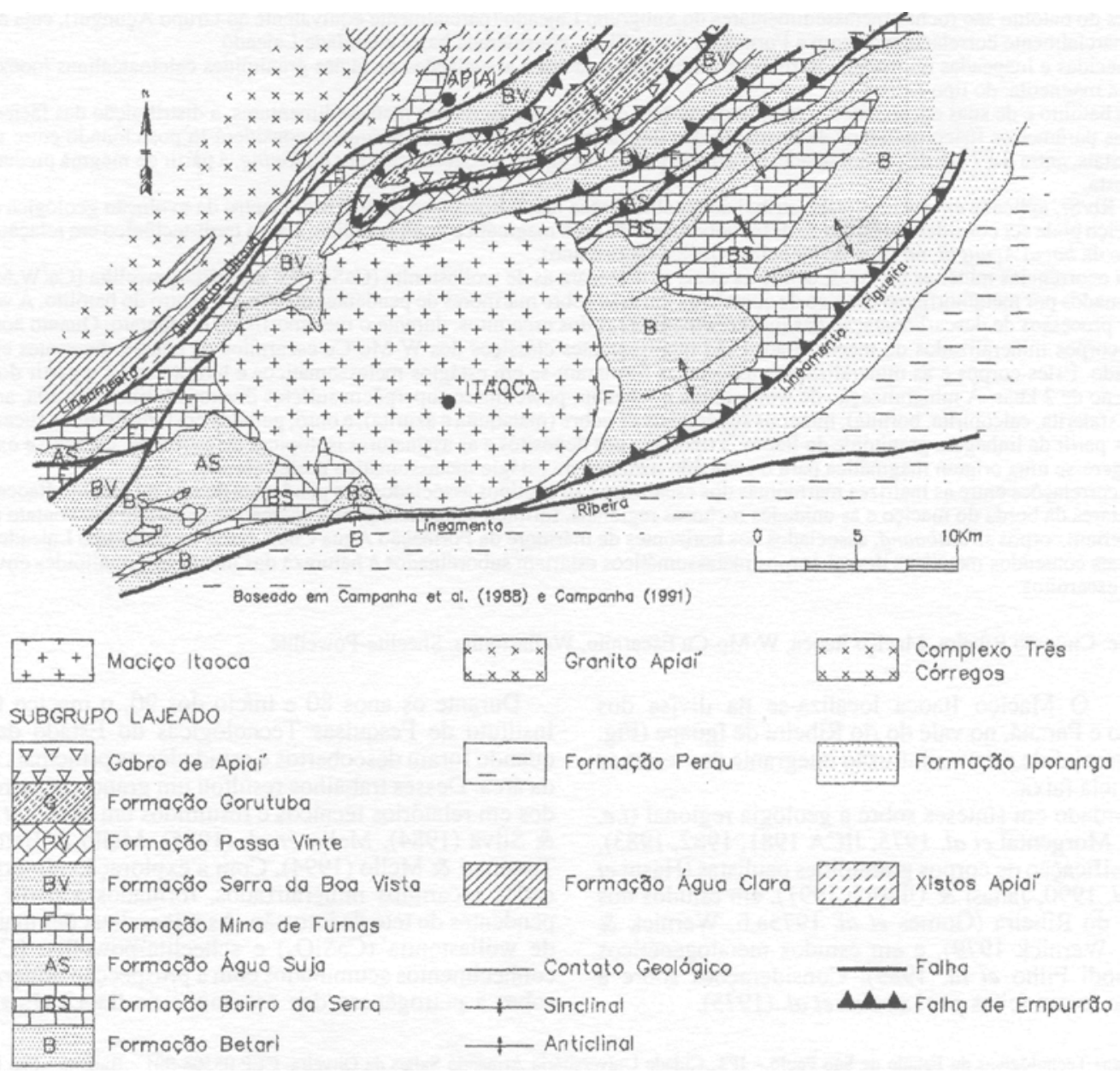

Figura 2 - Geologia das encaixantes do maciço Itaoca. 
porfiróides Cinza 1, e subordinadamente Cinza 2, e é constituída de monzogranitos, quartzo-monzonitos e, localmente, quartzo-sienitos cinzentos, todos com variações melanocráticas. De modo restrito, ocorrem rochas submetidas a alterações tardi a pós-magmáticas, designadas como Fácies Cinza 3, mineralizada com sulfetos diversos e compreendentes a monzogranitos hololeucocráticos cinza porfiróides.

A Unidade Saltinho constitui cerca de $20 \%$ da área do maciço, e se concentra a leste dc batólito. Corta a Unidade Itaoca como um stock e diversas apófises. $\mathrm{E}$ formada por duas fácies e uma associação de duas fácies intrusivas e consiste de monzogranitos e quartzo-sienitos róseos, porfiróides a eqüigranulares, com variações melanocráticas. Assim como a Unidade Itaoca, na Unidade Saltinho também ocorrem litotipos subordinados decorrentes de alterações tardi a pós-magmáticas, agrupados na Fácies Rósea 5, equivalentes a monzogranitos e quartzomonzonitos róseos, porfiróides, ineqüigranulares ou eqüigranulares.

A Unidade Milonftica formou-se às custas de monzogranitos e sienogranitos, geralmente porfiróides, cinzentos a róseos. Concentrase na borda sul da intrusão, onde ocupa por volta de $10 \%$ da área do batólito.

O conjunto de granitóides do maciço Itaoca foi submetido a processos pervasivos de feldspatizações potássica e sódica, que se intensificam nas fácies mais evoluídas do batólito. Localmente ocorrem greisens associados à zonas de cisalhamento que cortam o maciço. Alterações associadas aos greisens locais envolvem feldspatização, silicificação, turmalinização, argilização e saussuritização. Já na Unidade Milonftica, as alterações mais comuns parecem ser feldspatização e silicificação.

Natureza e evolução do maciço A composição mineral e química das fácies do maciço Itaoca as classificam como essencialmente metaluminosas, com saturação de alumínio em parte crescente nas fácies mais tardias ou submetidas a alterações tardi a pós-magmáticas (Fig. 5). O conjunto de fácies pode ser também considerado como da série calcio-alcalina de alto potássio de Lameyre \& Bowden (1982).

Diagramas litogeoquímicos sugerem que o maciço Itaoca abrange uma única linhagem de granitóides (Figs. 6 a 8). A Unidade Itaoca parece ser a mais precoce, e teria sido injetada pelos granitóides da Unidade Saltinho. A formação do maciço parece ter ocorrido pela sucessiva intrusão da Fácies Cinza 1 e Fácies Cinza 2, seguidas pelas fácies Rósea 1, Rósea 2, Rósea 3 e Rósea 4. As caraterísticas petrográficas, geoquímicas, radiométricas e as relações de campo entre as fácies indicam que o batólito teria sido formado a partir de injecões cogenéticas de magma do tipo I (Pitcher 1982,1987), gerado na base da crosta. As fácies foram possivelmente diferenciadas por cristalizacão fracionada, como sugere o aumento gradual das razões $\mathrm{Rb} / \mathrm{Sr}$ e a diminuição das razões $\mathrm{Ba} / \mathrm{Rb}$ das fácies menos evoluídas para as mais evoluídas. A fusão original pode ter recebido contribuicão de material mantélico, possibilidade sugerida por enclaves dioríticos possivelmente equivalentes a enclaves microgranulares escuros ou básicos, como definidos por (Didier 1987).

A disposição das fácies do maciço e as feições de deformação das encaixantes pelo batólito sugerem um posicionamento do mesmo por balloning (Ramsey 1981). A natureza do maciço e de suas encaixantes, aliadas à pressão de 2 kbar calculada por Ens (1990) para a formação dos escarnitos, sugerem um posicionamento a cerca de 6-7 km de profundidade. A raridade de pendentes do teto na Unidade Saltinho sugere que sua intrusão foi mais rasa, e qua estaria mais erodida que as demais.

Em diagramas clássicos, discriminantes da natureza tectono-magmática de corposígneos, o maciço Itaoca se classifica como pósorogênico pelos critérios de Pearce et al. (1984), tardi-orogênico (Batchelor \& Bowden 1985), do Grupo 1 (Harris et al 1986), e da Série Sintexia (Kequin et al. 1984).

Aspectos estruturais $\mathrm{O}$ maciço Itaoca aflora entre os lineamentos Quarenta Oitava, a noroeste, e Ribeira, a sul, ambos de natureza predominantemente dúctil (Fig. 3). Estes lineamentos pertencem às principais zonas de cisalhamento transcorrente regionais do final do Neoproterozóico (Campanha et al. 1994).

O maciço é cortado por zonas de cisalhamento dúcteis-rúpteis, de médio a alto ângulo, condicionantes da formação de cataclasitos e milonitos.

Todas as fácies intrusivas do maciço envolvem, além de granitóides isótropos, rochas com orientação mineral incipiente. Devido à má qualidade das exposições, a origem desta orientação é ainda incerta, podendo ser resultante de fluxo magmático ou de deformação por cisalhamento.
$\mathrm{Na}$ Unidade Milonítica, a deformação é mais intensa a sudoeste e a sul do macico. A sua ocorrência apenas nas proximidades do Lineamento Ribeira indica que a unidade resulta da movimentação transcorrente ao longo desta feição.

Alem disso, o padrão das falhas e zonas de cisalhamento nas encaixantes das bordas sul e sudeste do batólito, sugere a presença de um sistema de falhas em leque associados ao Lineamento Ribeira, que condicionaria as relações de contato entre as encaixantes do maciço e, parcialmente, entre elas e a intrusão.

Pendentes do teto $\mathrm{Na}$ área do plúton ocorrem corpos de rochas metassedimentares, subordinadamente metabásicas. Em todos corpos, os litotipos correspondem a rochas comuns das encaixantes ao maciço. Não há evidências de que esses corpos, expostos por centenas de metros a alguns quilômetros quadrados, tenham sido totalmente englobadas pelo magma, muito embora em pelo menos uma situação, no centro do batólito, ocorra o envolvimento parcial de massa considerável de metassedimentos por granitóides. Em vista disto, esses corpos podem ser interpretados como pendentes do teto da intrusão, em vez de mega-xenólitos.

Os litotipos dos pendentes são xistos, quartzitos, metarritmitos calcissilicáticos, mármores mais e menos puros, e restos de metabasitos derivados de intrusões de gabro no pacote metas sedimentar. Pela efeito térmico do granitóide, os restos de encaixantes estão, em maior ou menor grau, transformados em xistos mosqueados, hornfelses e, ocasionalmente, escarnitos, o conjunto constituindo o que foi chamado Unidade Termometamórfica Indiferenciada.

Ens (1990), embora tenha estudado mais os escarnitos da área, constata que os pendentes de teto da parte central do batólito (norte da vila Itaoca) foram inicialmente afetados por metamorfismo de contato de caráter isoquímico, em temperatura superior a $650{ }^{\circ} \mathrm{C}$. Posteriormente, com a progressiva consolidação magmática e atingida a saturação em $\mathrm{H}_{2} \mathrm{O}$ na massa ígnea, solucões aquosas iniciaram os processos metassomáticos responsáveis pela formação dos escarnitos, e pelas paragêneses retrógradas (moscovita poiquiloblástica nos xistos mosqueados e nos hornfelses e com tremolita e clinozoisita poiquiloblásticas nos mármores).

$\mathrm{Na}$ borda do macico, o metamorfismo termal é denunciado pela textura mosqueada dada por poiquiloblastos de moscovita ou andaluzita, em metapelitos, e pela recristalização de metacalcários.

Os pendentes de teto estão, em geral, mal expostos, impossibilitando melhor caracterização estrutural. Os trechos sondados mostram dobras com amplitude decamétrica a hectamétrica, fechadas a isoclinais, com mergulhos de camadas superiores a $50^{\circ}$. Localmente ocorrem feições de deformação intensa, tais como dobras intrafoliais, foliação plano-paralela ao bandamento composicional e transposição de camadas. A variação da direção das camadas e do bandamento composicional nos vários pendentes de teto indicam que os corpos foram afetados de modo distinto pela acão mecânica associada à ascensão dos pulsos magmáticos que constituíram o batólito. A direção geral N30-40 E das unidades encaixantes contrasta com as direções NNW e E-W dos pendentes, mesmo nas margens do batólito, sugerindo rotação generalizada, própria para cada bloco.

Escarnitos Ao norte da vila Itaoca (área Gorutuba, Fig. 3) ocorre um pendente de teto com aproximadamente $600 \mathrm{~m}$ por $400 \mathrm{~m}$ (Fig. 9), alongado segundo, a direção geral das camadas rochosas (N20-25 $\mathrm{W}$ ). Em profundidade, a sua extensão é superior a $200 \mathrm{~m}$, o limite das sondagens. O corpo está estru- turado em uma antiforme ligeiramente assimétrica, com plano axial segundo a direcão das camadas e com flancos que mergulham $60-70^{\circ}$ para NE e $70-80^{\circ}$ para SW. Do núcleo para as bordas a estrutura consiste, sucessivamente, de quartzito, moscovita-sillimanita hornfels, mármores, e uma seqüência rítmica de hornfelses calcissilicáticos e pelíticos.

$\mathrm{Da}$ ação de contato dos granitóides sobre os mármores resultou na formação de dois tipos de escarnitos.

Um ocorre no contato dos granitóides com mármores (corpos Gorutuba 2 e 3, Figs. 9 e 10) e é um escarnito escuro (Elliot 1982), ou piroxênio-granadífero (Smirnov 1982), denominado de granada-piroxênio escarnitos por Ens (1990). E de aparência maciça e compacta, verde-escura a marrom, de matriz fina a média, e constituído por agregados granoblásticos de salita/ferrosalita e granada (grossuláriaandradita), a qual também ocorre em porfiroblastos dispersos na matriz piroxenítica. $\mathrm{O}$ escarnito forma faixas decimétricas e métricas mais ou menos contínuas, que aumentam de volume e resultam em boi soes métricos a decametricos interacamadados no interior do mármore original. 
Tabela 1 - Legenda do mapa geológico do maciço Itaoca.

\section{LEGENDA}

\section{UNIDADES LITOESTRATIGRÁFICAS}

CENOZÓICO

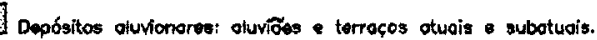

\section{MESOPROTEROZÓICO A NEOPROTEROZÓICO}

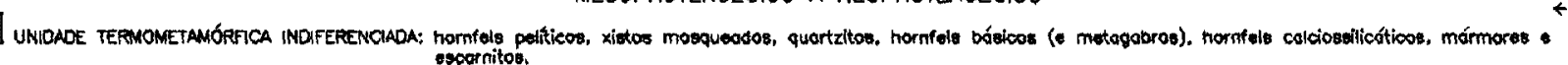

UNIDADE MILONITICA

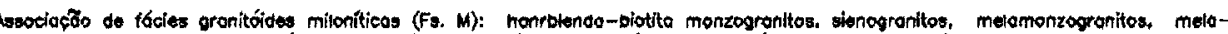

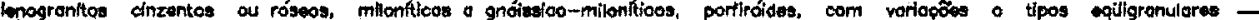
módios a grossos.

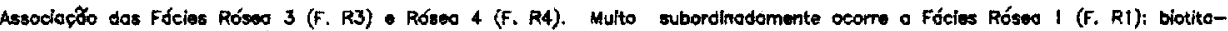

$X \times$ homblendo menzopronitos róososs eqüigranulores a inequilgremulares médios (F. R3). Hornblenda-biotlto monzogromitoe : quarizo-

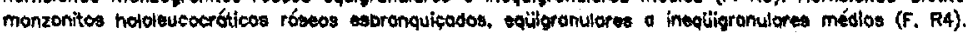

UNDAOEE SALTINHO

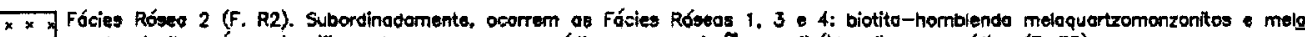
quartzosienitos rósecos inequígranulares, grossoso o móties, cam vorlacóes porfiróldes finas o módies (F. R2).

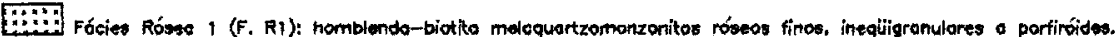

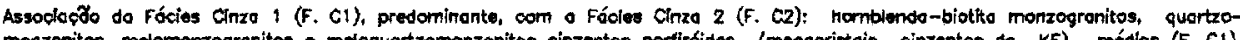

UNIDAOE TAOCA

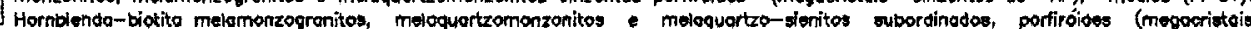
róseos de $\mathrm{KF}$ ), mécios a grossoss $\langle\mathrm{F}$. $\mathrm{CZ}$ ).

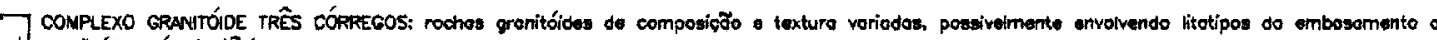
gronitoídes pós-tectōnicos.

$\nabla \nabla$ QABRO DE APIAS: metogabros - metadiabósios.

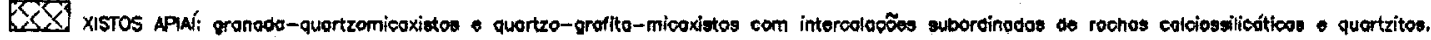

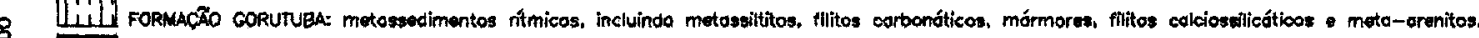

3 FORMACTO PASSA UNTE: mórmoros bondodos.

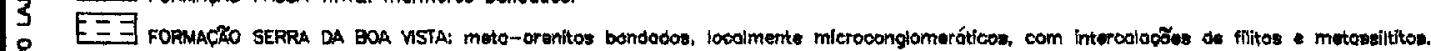

FORMACŨES BAIRRO DA SERRA E MINA DE FURNAS: mórmores - mórmoros

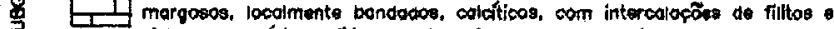

xistos corbonóticos, fflitos, motabositos moto-aronitos.

FOFMACZOO AGUA SUJA: mieoxlstos com intercaloçōes de

E-7 FORMACZO BETARI: quartzomizexistos, meta-orenitos e metoconqlomorodos.

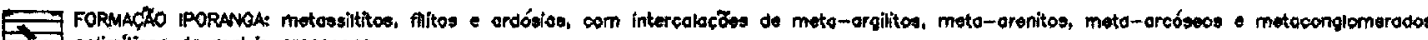
polimiticos de matriz areoseono.

FORMACZO PERAN: filitos xistos finos, motoswititos, quartzitos,

WIIT filtos grafitosos, meteritmitou, orobsios o motabasitos. Subordinedament ocarrem metomuleânions bósicas - ócidos.
FORMACÃO ÁGUA CLARA: POOhos colgiosellicótions.

[1] cácio-xistos, mármores o intercalecónes mubordinodos de quortzitos. xistos, metabositos, metoUttramafitos, filitos paragnaisess.

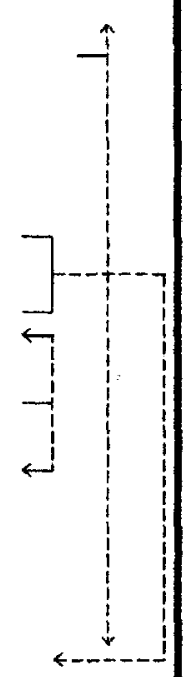

- Conteto iftico sefinida

Limite entre fócies, ossocioởas de fócios ou unidades granitóides

Tefinido, - Inferide,

Fotho ou zond do choolhomento definids ou províver

Folko ou zono de cloothomento inferido

D. Folnd ou zond de cisolhomento definida, ou provóvel, corn baixo mergutho

- Falna ou zona de elsathamento inferida. com bolxe mergulho

Falho. zone de ciscthamento, ou froturo fotointerprotedo no domínio granitólde

$x$ Sinelinal

$\lambda-$ Sinelinal inferido

Antielinal

2x Antielinal inforido
CONVENÇ̃̃ES GEOLÓGICAS

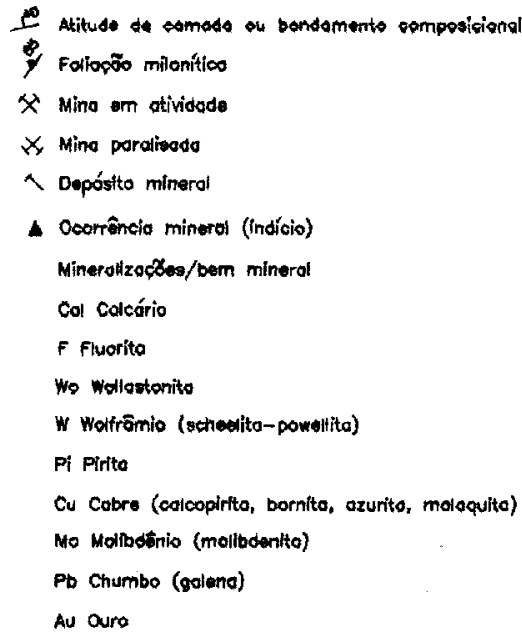

Corpes litisas of litotipot som dimenesose

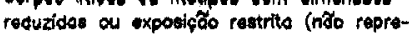
sentáveis no do mopo)

- xq Xistos, xistos mosqueodos - quartzitos

- $m$ Mármeres

- Escarnitos

- ms Metagobros

- I Lomprófiros

- or (F, C3) Cranitôtdes (com indicaç\%o de fócies)

Fúcies Girzo 3 (F, GS); biotito montogranitos

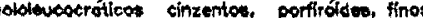
a modlos.

Fácies Rósess 5 (Fs. RS): hornblende-biotito menzoprenitos quartzomonzonilos rósosos. porfiróides, com voriacótos inequigronulares: pailigronularss, finos a mésios. 


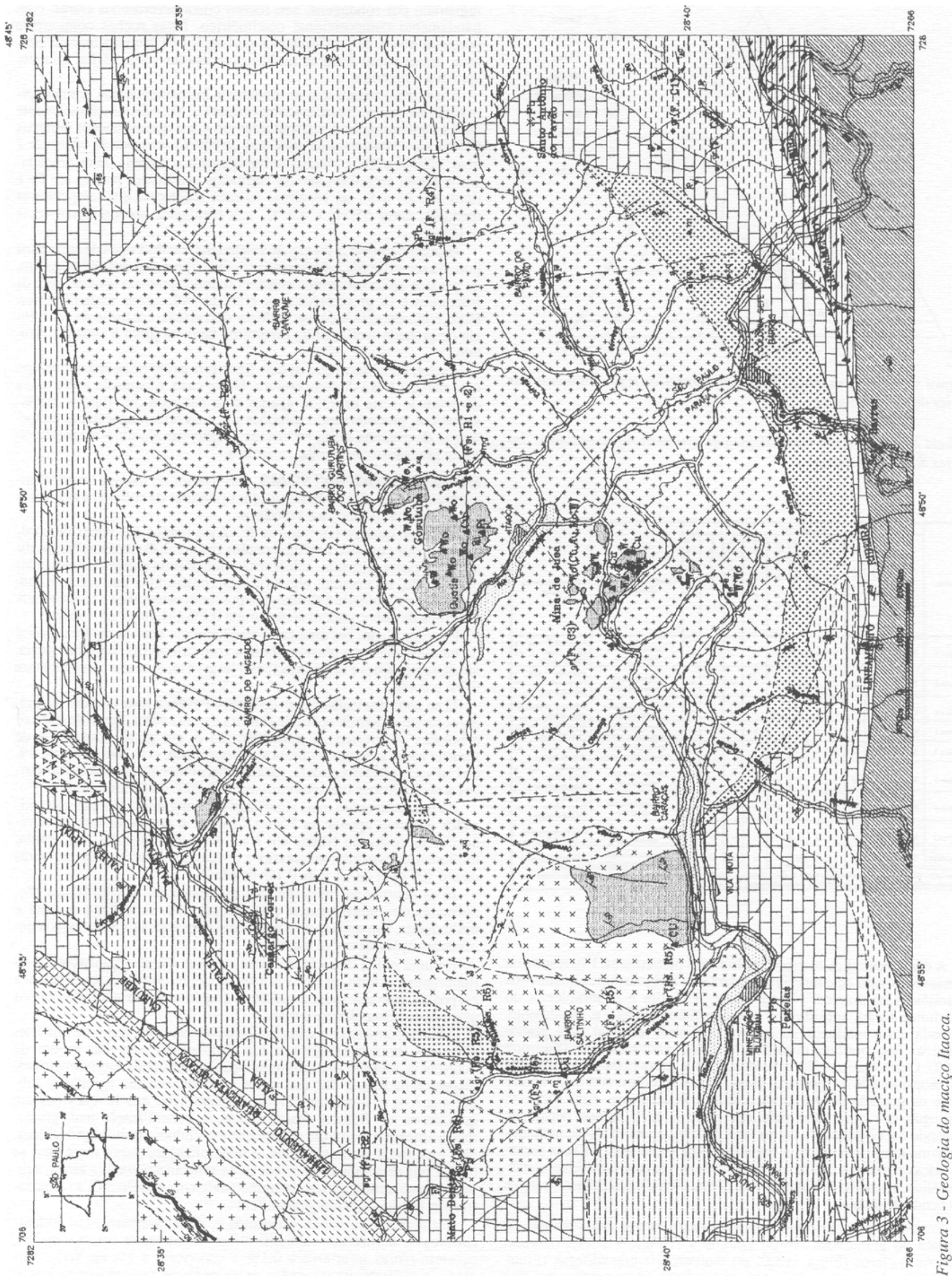




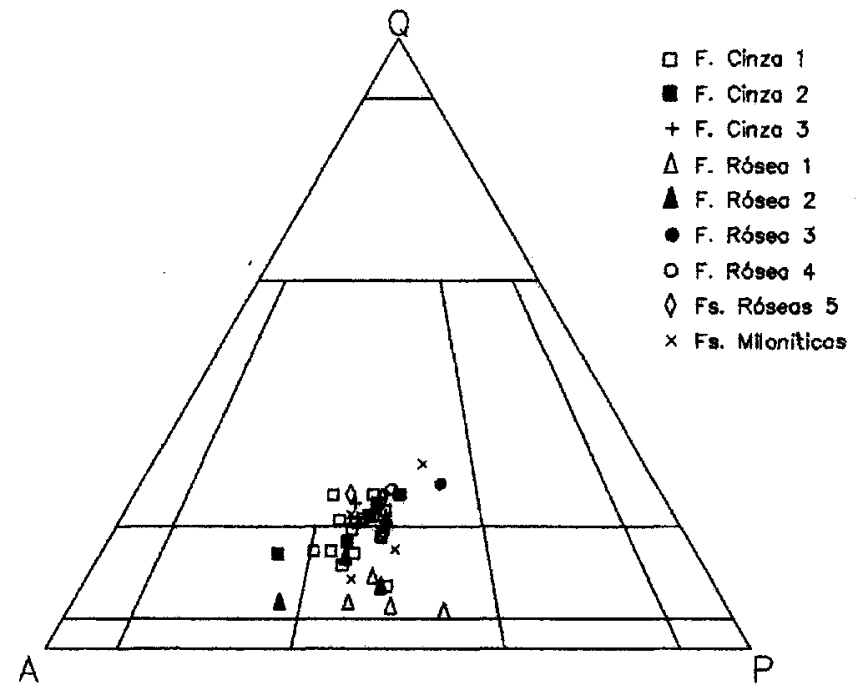

Figura 4 - Diagrama modal QAP para amostras representativas das fades do maciço Itaoca.

Tabela 2 - Composição mineralógica de amostras representativas das fades do maciço Itaoca.

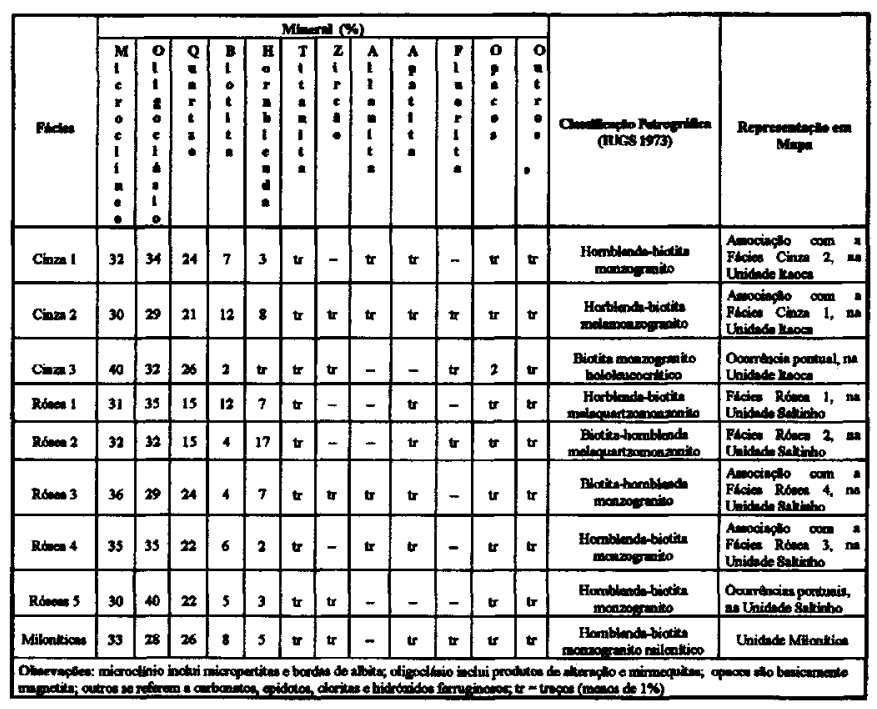

A esses escarnitos se associam litotipos particulares. Um resulta de metassomatismo de contato impresso tanto nos mármores quanto nos granitóides adjacentes. Nesses casos, a biotita e a hornblenda do granitóide foram substituídos por diopsídio, epidoto e, localmente, granada, com mudança da textura porfiróide original para granoblástica. Isto permite classificá-la como endoescarnito (Smirnov 1882). Outro é uma rocha esverdeada, fina, granoblástica, constituída por diopsídio (50\%), granada, plagioclásio, epidoto e quartzo, e ocorre entre os granada-piroxênio escarnitos e o mármore. Esta rocha se distingue dos escarnitos pela cor mais clara e menor densidade podendo ser considerada como halo periférico resultante de metassomatismo mais brando que o registrado nos escarnitos. As suas características permitem classificá-la como hornfels calcissilicático metassomático, e, assim, distingui-la dos demais hornfelses calcissilicáticos do pendente do teto.

Em outros pontos deste mesmo pendente do teto, mais distante do contato do granitóides (corpo Gorutuba 1, Figs, 9 e 11), ocorrem escarnitos claros (Elliot 1982.) ou wollastonita-granadíferos (Smirnov 1982), designados como granada-wollastonita escarnitos por Ens
(1990). Constituem um corpo com cerca de $200 \mathrm{~m}$ de comprimento, em média $8 \mathrm{~m}$ de largura e com profundidade superior a $150 \mathrm{~m}$, como registrado por sondagens. São rochas cinza-esverdeadas claras, com bandamento composicional centimétrico. Estas rochas comumente possuem níveis de porfiroblastos ou bolsões de granada maciça marrom, assim como fraturas tardias preenchidas com calcita, quartzo, apofílita e prehnita.

Ens (1990) sugere que os elementos introduzidos nos granada-piroxênio escarnitos foram essencialmente $\mathrm{Fe}, \mathrm{Mg}$ e Si, simultaneamente com a contaminação dos granitóides em $\mathrm{Ca}$, e que as reações minerais ocorreram a temperaturas próximas de $600^{\circ} \mathrm{C}$, pressões da ordem de 2 kbar, $f \mathrm{CO}_{2} \geq$ a 0,5 , e condições inicialmente redutoras. Já os granadawollastonita escarnitos seriam formados por fluidos pobres em $\mathrm{Fe}$ e ricos em $\mathrm{Al}$ e $\mathrm{Si}$, ao reagirem com os mármores em temperaturas menores, entre $550^{\circ} \mathrm{C} \mathrm{e} 450^{\circ} \mathrm{C}$, sob condições predominantemente oxidantes.

Hipoteticamente, a formação seqüencial dos dois tipos de escarnitos poderia ser atribuída à distância entre cada tipo e os granitóides. Assim, os granada-salita escarnitos estariam situados junto ao contato entre os mármores e os granitóides e os granada-wolastonita mais distantes. Hoje, contudo, esta hipótese pode ser descartada, em razão da ocorrência de granada-wollastonita escarnitos também junto à zona de contato.

Assim, acredita-se que os dois tipos formaram-se ao mesmo tempo e na mesma faixa de temperatura. Neste caso, o controle sobre a sua diversidade seria exercido apenas pela natureza dos fluidos metassomáticos, predominando soluções silicosas ferromagnesianas na formação de granada-salita escarnitos, e silicosas alumino-magnesianas na de granada-wollastonita escarnitos.

OCORRÊNCIAS MINERAIS No interior do maciço há mineralizações diversas, desde disseminações pontuais de sulfetos a depósitos cubados de wollastonita e volfrâmio.

Veios de quartzo em fraturas de vários pontos das zonas de cisalhamento que cortam o batólito contém, em geral, disseminações localizadas de pirita, pirrotita, calcopirita, molibdenita e galena, associadas ou não. Há, no entanto, alguns filões constituídos por brechas com turmalina na Unidade Saltinho que possuem calcopirita e pirita e onde os teores de cobre podem alcançar até $0,1 \%$ (Mello et al. 1981).

Por outro lado, em uma zona cisalhamento situada na área central do batólito, ocorrem blastomilonitos com calcopirita, bornita e pirita, em disseminações e níveis maciços. Neste caso, os teores de cobre entre $0,2 \%$ e $0,4 \%$.

Já na zona de cisalhamento do Bairro Pavão, a leste do maciço (Fig. 3), ocorrem mineralizações de fluorita em milonitos, veios de quartzo e bolsões de greisen. A mineralização é, em geral, constituída de fluorita roxa, amarela ou branca, disseminada, com teores de até $4 \%$ de $\mathrm{CaF}_{2}$. Os greisens podem, localmente, conter agregados centimétricos a decimétricos maciços com mais de $80 \%$ de fluorita roxa.

As mineralizações mais significativas em granitóides não milonitizados ocorrem apenas na Fácies Cinza 3 e compreendem disseminações na rocha ou filmes em fraturas contendo pirita, calcopirita, molibdenita, pirrotita, marcassita e covelita, condicionantes de teores de até $300 \mathrm{ppm}$ de $\mathrm{Cu}$ e de $0,1 \%$ de $\mathrm{MoO}_{3}$.

Já as ocorrências minerais nos escarnitos do maciço Itaoca são, normalmente, representadas por wollastonita, scheelita-powellita e molibdenita. Em apenas uma ocorrência observa-se a associação com mineralizações de cobre e ouro.

Há uma nítida dissociação entre os tipos das mineralizações mais importantes. Assim, os depósitos de scheelita-powellita se associam a corpos de granada-salita escarnitos, enquanto os de wollastonita aos granada-wollastonita escarnitos.

As concentrações de scheelita-powellita são agregados de minerais cinzentos (branco-azulados, à luz ultravioleta) com dois modos de ocorrência. Ora são finas disseminações de minerais submilimétricos, dispersos na matriz dos escarnitos salíticos, ora são agregados submilimétricos a subcentimétricos, concentrados nos níveis ricos em granada ou nas fraturas dessas rochas. A mineralização mais grossa, relativamente mais tardia (?), ocorre em endoescarnitos epidosíticos. Nos escarnitos wollastoníticos, a mineralização, muito mais rara, se traduz por disseminações erráticas de scheelita-powellita cinza, submilimétrica a milimétrica, aparentemente com tendência a se concentrar em fraturas e níveis granadíferos.

Em granada-piroxênio escarnitos e, mais raramente, em endoescarnitos e hornfelses calcissilicáticos metassomáticos associados, ocorrem teores inferiores a $0,1 \%$ a superiores a $2 \%$ de $\mathrm{WO}_{3}$. Nos granada-wollastonita escarnitos, esses teores decrescem para menos de 
Tabela 3 - Composição química (elementos maiores) das fades do maciço Itaoca

\begin{tabular}{|c|c|c|c|c|c|c|c|c|c|c|c|c|c|c|c|c|c|}
\hline \multicolumn{17}{|c|}{ Elementos (\%) } & \multirow[t]{2}{*}{ Ficles } \\
\hline $\mathrm{Sw}_{2}$ & $\mathrm{Al}_{2} \mathbf{O}_{3}$ & $\mathrm{Fe}_{3} \mathrm{O}_{3}$ & FeO & $\mathrm{CaO}$ & $\mathrm{M}=\mathrm{O}$ & $\mathrm{N}_{2} \mathrm{O}$ & $\mathbf{K}_{2} \mathbf{O}$ & Mno & $\mathrm{THO}_{2}$ & $\mathbf{P}_{2} \mathbf{O}_{3}$ & Bmo & $\mathbf{F}$ & $\mathbf{s}$ & $\mathrm{CO}_{3}$ & $\mathbf{H}_{3} \mathbf{O}^{+}$ & Total & \\
\hline 62,5 & 15,3 & 1,7 & 3,3 & 3,7 & 1,8 & 3,8 & 4,9 & 0,05 & 1,0 & 0,47 & 0,27 & 0,14 & 0,006 & 0,10 & 0,79 & 99,83 & \multirow{4}{*}{ Cinza 1} \\
\hline 63,4 & 15,6 & 1,4 & 3,1 & 3,5 & 1,6 & 3,9 & 5,0 & 0,04 & 0,95 & 0,41 & 0,28 & 0,12 & 0,012 & 0,10 & 0,40 & 99,81 & \\
\hline 67,0 & 14,8 & 1,2 & 2.2 & 2,8 & 1,2 & 3,9 & 5,0 & 0,03 & 0,75 & 0,34 & 0,23 & 0,12 & 0,006 & 0,10 & 0,19 & 99,87 & \\
\hline 64,3 & 15,3 & $<0,1$ & 4,0 & 3,1 & 1,7 & 3,7 & 5,4 & 0,04 & 0,94 & 0,43 & 0,30 & 0,11 & 0,006 & 0,15 & 0,33 & 99,81 & \\
\hline 67,2 & 14,6 & 1,1 & 2,0 & 2,5 & 1,3 & 3,8 & 5,5 & 0,04 & 0,70 & 0,38 & 0,22 & 0,13 & 0,007 & 0,10 & 0,38 & 99,96 & \multirow{4}{*}{ Cinza 2} \\
\hline 68,8 & 14,6 & 1,1 & 1,6 & 2,1 & 0,9 & 3,5 & 5,4 & 0,03 & 0,60 & 0,26 & 0,21 & 0,11 & 0,006 & 0,10 & 0,56 & 99.89 & \\
\hline 65,8 & 15,2 & 1,0 & 2,3 & 2,8 & 1,2 & 3,5 & 5,5 & 0,04 & 0,82 & 0,41 & 0,26 & 0,12 & 0,007 & 0,25 & 0,62 & 99,83 & \\
\hline 65,0 & 15,4 & 1,1 & 2,3 & 29 & 1,4 & 3,3 & 5,7 & 0,04 & 0,77 & 0,36 & 0,28 & 0,10 & 0,008 & 0,60 & 0,62 & 99,88 & \\
\hline 72,0 & 14,5 & 0,5 & 0,79 & 0,8 & 0,4 & 3,4 & 5,7 & $<0,01$ & 0,43 & 0,22 & 0,20 & 0,06 & 0,64 & 0,15 & 0,31 & 100,12 & \multirow[t]{2}{*}{ Cinza 3} \\
\hline 70,4 & 14,4 & 1,1 & 1,1 & 1,3 & 0,6 & 3,7 & 5,0 & $<0,01$ & 0,61 & 0,29 & 0,17 & 0,01 & 0,93 & 0,15 & 0,30 & 100,23 & \\
\hline 64,4 & 14,5 & 1,0 & 2,7 & 3,3 & 1,7 & 3,4 & 5,8 & 0,09 & 0,77 & 0,46 & 0,28 & 0,12 & 0,007 & 0,90 & 0,35 & 99,98 & \multirow{3}{*}{ Rósea 1} \\
\hline 62,5 & 14,1 & 1,9 & 3,0 & 3,6 & 1,8 & 3,0 & 5,9 & 0,08 & 0,86 & 0,52 & 0,28 & 0,11 & 0,012 & 1,4 & 0,73 & 99,79 & \\
\hline 64,5 & 14,3 & 1,7 & 2,6 & 3,1 & 1,9 & 3,1 & 5,9 & 0,06 & 0,85 & 0,49 & 0,28 & 0,15 & 0,006 & 0,50 & 0,44 & 99,88 & \\
\hline 65,8 & 14,5 & 0,6 & 3,0 & 3,0 & 1,8 & 3,2 & 5,8 & 0,05 & 0,74 & 0,46 & 0,26 & 0,15 & 0,016 & 0,15 & 0,48 & 99,98 & \multirow{3}{*}{ Rósea 2} \\
\hline 65,7 & 14,2 & 1,1 & 2,3 & 2,9 & 1,6 & 3,3 & 5,4 & 0,04 & 0,70 & 0,41 & 0,24 & 0,09 & 0,008 & 1,2 & 0,69 & 99,88 & \\
\hline 66,3 & 14,3 & 1,5 & 2,0 & 2,8 & 1,6 & 3,5 & 5,6 & 0,05 & 0,69 & 0,43 & 0,25 & 0,10 & 0,005 & 0,15 & 0,53 & 99,81 & \\
\hline 69,8 & 14,2 & 0,4 & 1,9 & 2,2 & 0,9 & $\mathbf{3 , 5}$ & 5,3 & 0,04 & 0,50 & 0,30 & 0,19 & 0,13 & 0,031 & 0,15 & 0,38 & 99,93 & \multirow[t]{2}{*}{ Rósea 3} \\
\hline 70,2 & 14,3 & 0,4 & 1,9 & 2,0 & 0,9 & 3,7 & 5,1 & 0,02 & 0,46 & 0,29 & 0,20 & 0,15 & 0,005 & 0,15 & 0,17 & 99,91 & \\
\hline 71,5 & 14,9 & 0,8 & 1,3 & 1,7 & 0,5 & 2,6 & 5,6 & 0,02 & 0,43 & 0,21 & 0,14 & 0,09 & 0,006 & 0,15 & 0,08 & 99,97 & \multirow{4}{*}{ Rósea 4} \\
\hline 72,1 & 14,7 & 0,7 & 1,1 & 1,4 & 0,3 & 3,5 & 5,4 & 0,03 & 0,31 & 0,14 & 0,09 & 0,07 & 0,005 & 0,15 & 0,04 & 100,04 & \\
\hline 71,6 & 14,4 & 0,4 & 1,3 & 1,5 & 0,5 & 3,8 & 5,2 & 0,01 & 0,35 & 0,19 & 0,17 & 0,06 & 0,007 & 0,15 & 0,36 & 99,91 & \\
\hline 70,9 & 14,6 & 1,3 & 1,0 & 1,7 & 0,5 & 3,5 & 5,2 & 0,02 & 0,46 & 0,21 & 0,13 & 0,06 & 0,005 & 0,15 & 0,20 & 99,89 & \\
\hline 69,8 & 14,7 & 0,7 & 1,4 & 1,7 & 0,9 & 4,0 & 5,4 & 0,02 & 0,45 & 0,26 & 0,20 & 0,13 & 0,005 & 0,10 & 0,17 & 99,93 & \multirow{3}{*}{ Róseas 5} \\
\hline 70,4 & 14,7 & 0,5 & 1,6 & 1,4 & 0,8 & 4,0 & 5,3 & 0,01 & 0,45 & 0,26 & 0,21 & 0,10 & 0,005 & 0,10 & 0,16 & 99,97 & \\
\hline 70,1 & 14,4 & 1,1 & 1,1 & 1,6 & 0,5 & 3,8 & 5,2 & 0,02 & 0,43 & 0,23 & 0,13 & 0,10 & 0,005 & 0,75 & 0,42 & 99,92 & \\
\hline 70,6 & 14,4 & 0,7 & 1,4 & 1,8 & 0,6 & 4,0 & 3,2 & 0,03 & 0,44 & 0,23 & 0,17 & 0,12 & 0,005 & 0,10 & 0,07 & 99,90 & \multirow{3}{*}{ Miloniticas } \\
\hline 69,0 & 14,5 & 0,9 & 1,1 & 2,1 & 0,5 & 4,3 & 4,6 & 0,01 & 0,41 & 0,22 & 0,18 & 0,10 & 0,005 & 1,4 & 0,48 & 99,81 & \\
\hline 72,0 & 14,8 & 1,2 & 1,0 & 1,5 & 0,5 & 2,1 & 5,3 & 0,02 & 0,43 & 0,24 & 0,17 & 0,14 & 0,006 & 0,15 & 0,24 & 99,84 & \\
\hline
\end{tabular}

Tabela 4 - Composição química (elementos menores) das fácies do maciço Itaoca

\begin{tabular}{|c|c|c|c|c|c|c|c|c|c|c|c|c|c|c|c|c|}
\hline \multicolumn{16}{|c|}{ Elementos (ppm) } & \multirow{2}{*}{ Fácles } \\
\hline c1 & Ba & $\mathrm{Sr}$ & Th & C: & $\mathbf{Z r}$ & $\mathbf{N b}$ & $\mathbf{R} \mathbf{b}$ & $\mathbf{U}$ & $\mathbf{w}$ & Sn & Mo & $\mathbf{Y}$ & $\mathbf{L i}$ & $\mathbf{P b}$ & $\mathbf{Z n}$ & \\
\hline 98 & 2440 & 1350 & $\leq 10$ & $<10$ & 390 & 16 & 92 & 4 & $<3$ & $<5$ & $<5$ & 43 & $<5$ & 10 & 61 & \multirow{4}{*}{ Cinza I } \\
\hline 100 & 2500 & 1440 & $<10$ & $<10$ & 380 & 15 & 99 & 4 & $<3$ & $<s$ & $<5$ & 38 & $<5$ & 9 & 57 & \\
\hline 47 & 2070 & 1130 & $<10$ & $<10$ & 310 & 15 & 110 & 5 & $<3$ & $<5$ & $<5$ & 22 & $<5$ & 7 & 46 & \\
\hline 57 & 2640 & 1290 & $<10$ & $<10$ & 360 & 14 & 100 & 2 & $<3$ & $<5$ & $<5$ & 29 & $<9$ & 11 & 55 & \\
\hline 39 & 2010 & 1160 & $<10$ & $<10$ & 290 & 11 & 130 & 6 & $<3$ & $<5$ & $<5$ & 12 & $<5$ & 21 & 43 & \multirow{4}{*}{ Cinza 2} \\
\hline 16 & 1860 & 1040 & $<10$ & $<10$ & 270 & 16 & 140 & 3 & $<3$ & $<5$ & $<5$ & 22 & $<5$ & 14 & 54 & \\
\hline 38 & 2350 & 1300 & $<10$ & $<10$ & 310 & 14 & 120 & 4 & $<3$ & $<5$ & $<5$ & 29 & $<5$ & 11 & 50 & \\
\hline 45 & 2470 & 1320 & $<10$ & $<10$ & 340 & 15 & 110 & 5 & $\leq 3$ & $\leq 5$ & $<5$ & 22 & $<5$ & 14 & 54 & \\
\hline 150 & 1580 & 740 & 18 & $<10$ & 240 & 12 & 180 & 3 & $<3$ & $\leq s$ & $<5$ & $\leq 10$ & $<5$ & 14 & 11 & \multirow[t]{2}{*}{ Cinza 3} \\
\hline 78 & 1560 & 770 & 13 & $\leq 10$ & 240 & 12 & 140 & 7 & 3 & $\leq 5$ & $<5$ & 17 & $\leq 5$ & 15 & 17 & \\
\hline 61 & 2490 & 1100 & $<10$ & $<10$ & 370 & 18 & 120 & 6 & 3 & $<3$ & $<5$ & 29 & $\leq 5$ & 26 & 44 & \multirow{3}{*}{ Rósea 1} \\
\hline 140 & 2500 & 1080 & $<10$ & $\leq 10$ & 410 & 23 & 130 & 7 & 3 & $<5$ & $<5$ & 29 & $<5$ & 26 & 61 & \\
\hline 170 & 2500 & 1170 & $<10$ & $<10$ & 400 & 20 & 130 & 3 & $<3$ & $<5$ & $<5$ & 32 & $<5$ & 21 & 56 & \\
\hline 140 & 2330 & 1100 & $<10$ & $<10$ & 320 & 15 & 120 & 7 & 3 & $<5$ & $<5$ & 28 & $\leq 5$ & 15 & 34 & \multirow{3}{*}{ Rósea 2} \\
\hline 76 & 2120 & 1100 & $<10$ & $<10$ & 330 & 18 & 140 & 6 & 3 & $<5$ & $<5$ & 17 & $\leq 5$ & 14 & 56 & \\
\hline 39 & 2210 & 1130 & $<10$ & $<10$ & 350 & 21 & 150 & 7 & $<3$ & $<5$ & $<5$ & 28 & $<5$ & 17 & 41 & \\
\hline$<10$ & 1680 & 890 & 17 & $<10$ & 260 & 15 & 130 & 6 & 3 & $<5$ & $<5$ & 17 & $<5$ & 19 & 30 & \multirow[t]{2}{*}{ Rósea 3} \\
\hline 11 & 1790 & 900 & $<10$ & $<10$ & 250 & $<10$ & 140 & 5 & $<3$ & $<5$ & $<5$ & 38 & $<5$ & 21 & 37 & \\
\hline$<10$ & 1250 & 810 & $<10$ & $<10$ & 250 & 10 & 120 & 2 & 3 & $<5$ & $<5$ & 17 & $<s$ & 8 & 39 & \multirow{4}{*}{ Rósea 4} \\
\hline$<10$ & 840 & 630 & $<10$ & $<10$ & 210 & 10 & 120 & 5 & 3 & $<5$ & $<5$ & 17 & $\leq 5$ & 8 & 38 & \\
\hline 31 & 1550 & 850 & $\leq 10$ & $<10$ & 240 & 10 & 140 & 4 & $<3$ & $<3$ & $\leq 5$ & 11 & $<5$ & 18 & 40 & \\
\hline 22 & 1140 & 770 & $<10$ & $<10$ & 250 & 16 & 130 & 4 & 3 & $<5$ & $<5$ & $<10$ & $<5$ & 8 & 42 & \\
\hline 26 & 1780 & 950 & $<10$ & $<10$ & 260 & 13 & 150 & 5 & 3 & $\leq 5$ & $<3$ & $<10$ & $\leq 5$ & 17 & 46 & \multirow{3}{*}{ Róseas 5} \\
\hline 11 & 1860 & 990 & 14 & $\leq 10$ & 280 & 11 & 150 & 7 & $\leq 3$ & $\leq 5$ & $\leq 5$ & 22 & $\leq 5$ & 13 & 49 & \\
\hline 49 & 1200 & 740 & $<10$ & $<10$ & 240 & 10 & 140 & 3 & 3 & $<3$ & $<5$ & 12 & $<5$ & 14 & 39 & \\
\hline$<10$ & 1530 & 920 & $<10$ & $\leq 10$ & 260 & 13 & 180 & 7 & 3 & $<5$ & $<5$ & 17 & $<3$ & 14 & 33 & \multirow{3}{*}{ Miloniticas } \\
\hline 23 & 1610 & 770 & $<10$ & $<10$ & 240 & 12 & 140 & 7 & $\leq 3$ & $\leq 5$ & $\leq 5$ & $\leq 10$ & $<5$ & 20 & 44 & \\
\hline 39 & 1510 & 770 & 18 & $\leq 10$ & 240 & 13 & 180 & 7 & $<3$ & $<3$ & $\leq s$ & $\leq 10$ & $<5$ & 16 & 44 & \\
\hline
\end{tabular}




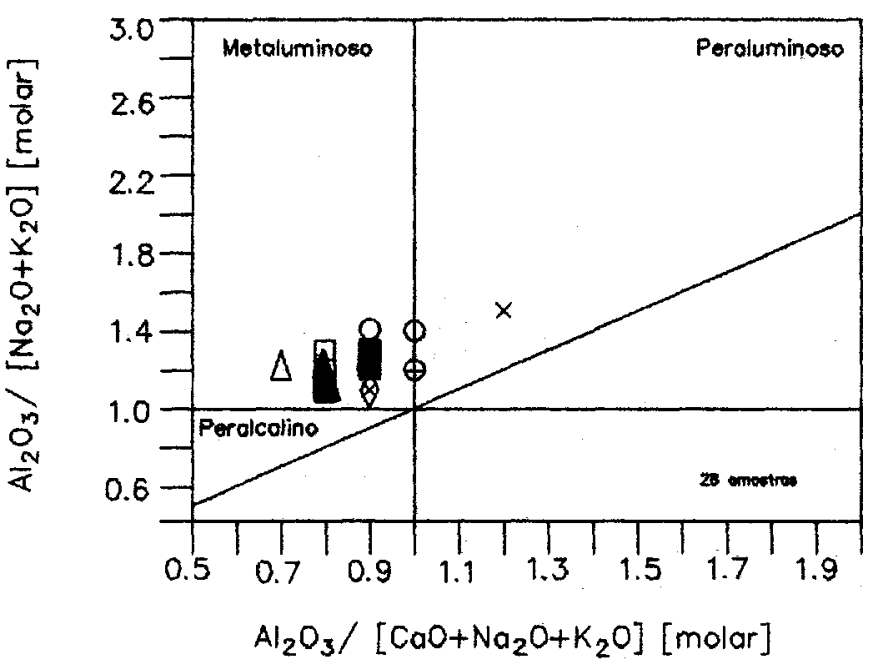
- F. Cinza 1
$\Delta$ F. Roseo 1
- F. Róseo 4
- F. Clnzo 2
A F. Rosed 2
- Fs Róseas 5
$+F$. Cinza 3
- F. Rósea 3
$x$ Fs. Miloniticos

Figura 5 - indices de Shand em diagrama de Maniar \& Piccoli (1989) para amostras das fades do maciço Itaoca.
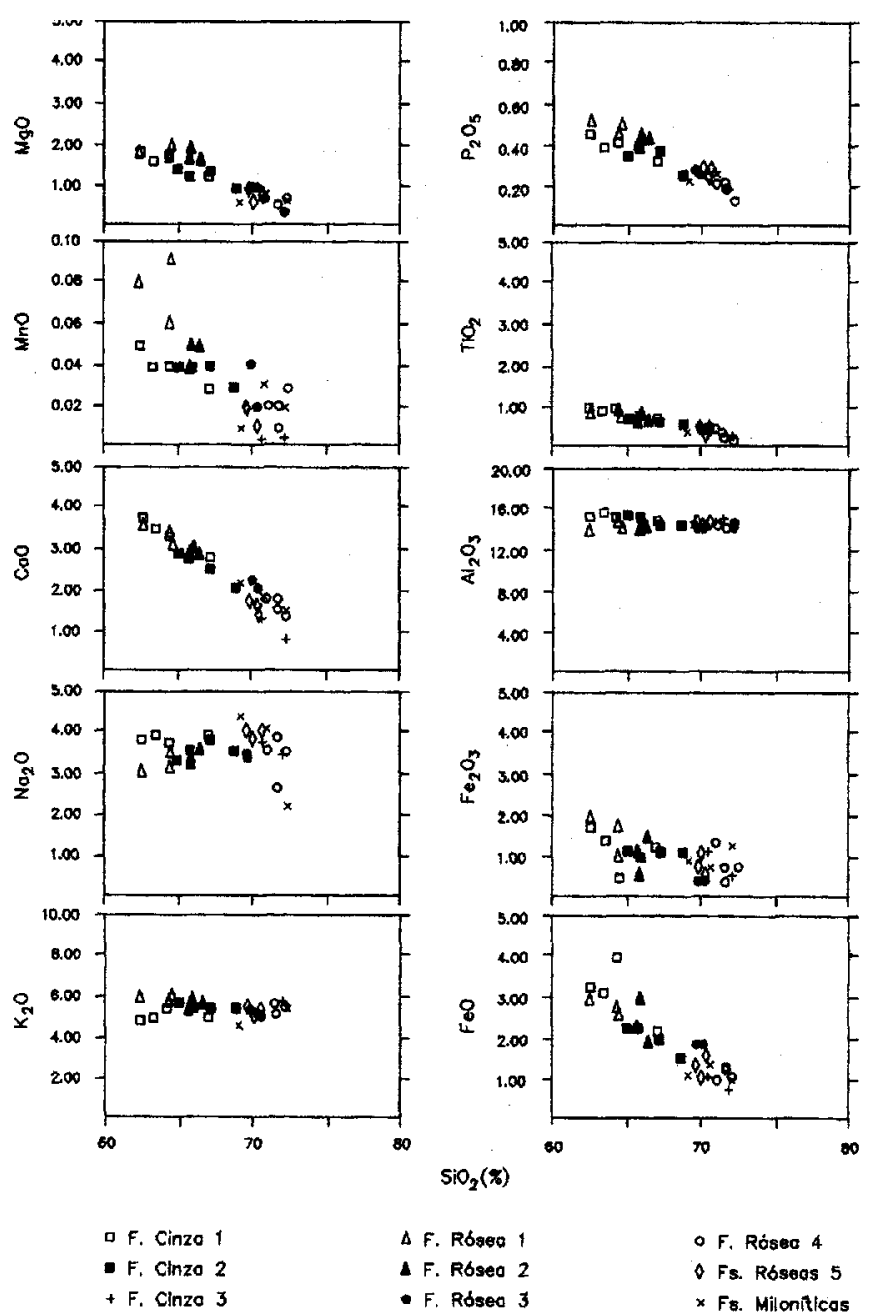

- F. Rósec 4

OFs. Rosseos 5

$\times$ F. Miloniticos
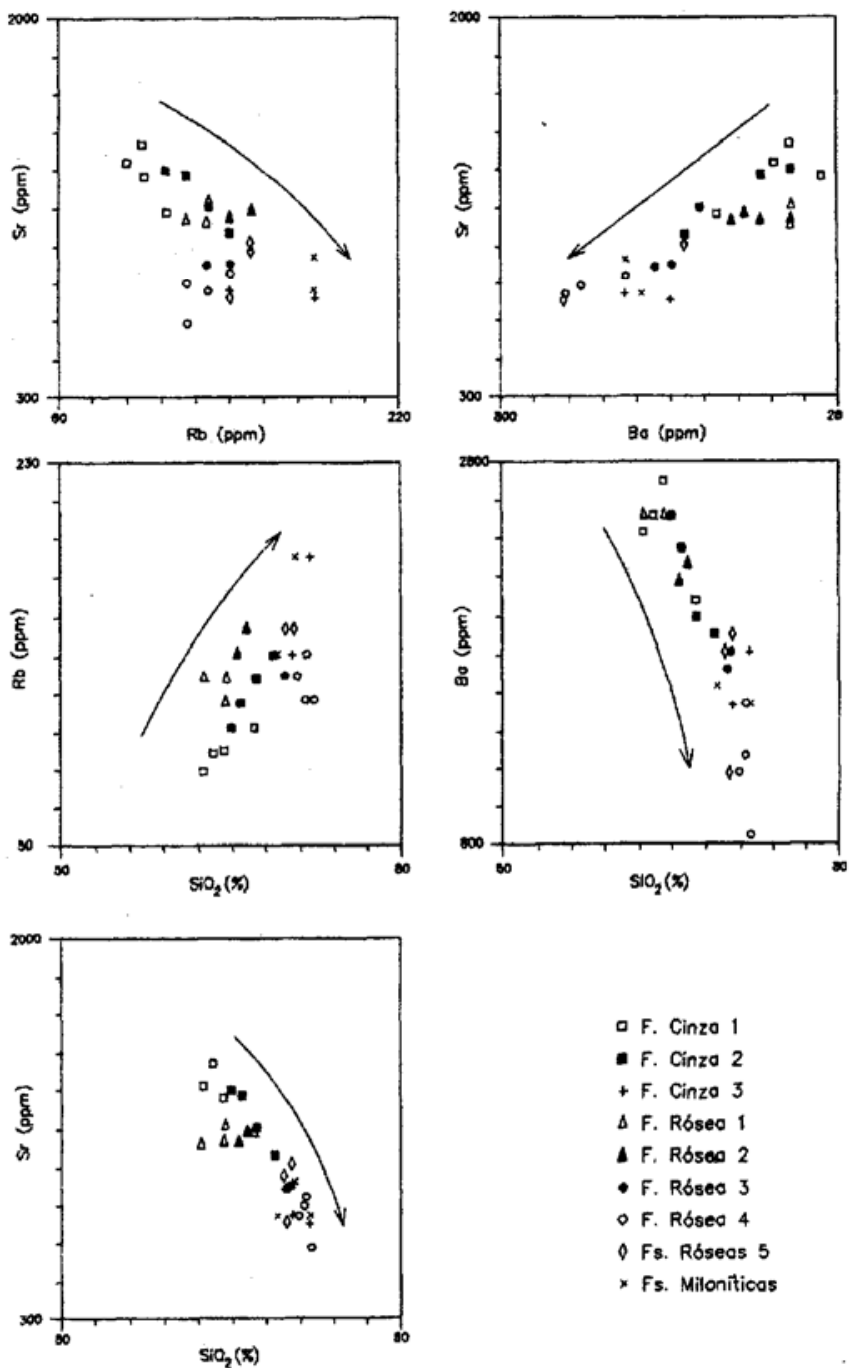

F. Cinzo 1
F. Cinzo 2
F. Cinzo 3
F. Róseo 1
F. Rósed 2
- F. Róseo 3
- F. Rósed 4
Fs. Róseos 5
Fs. Miloníticos

Figura 7 - Diagramas de variação de elementos traços, e elementos traço e silica nas fades do maciço Itaoca.

$0,03 \%$ a $0,05 \%$ de $\mathrm{WO}_{3}$ na rocha total, muito embora possam ocasionalmente alcançar até $0,9 \%$ de $\mathrm{WO}_{3}$. Teores de molibdênio podem ser desconsiderados nesse segundo caso, aumentando para até $0,5 \%$ de $\mathrm{MoO}_{3}$ nos granada-salita escarnitos e hornfels calciossilicáticos metassomáticos. Nestas últimas rochas, em particular, os teores de molibdênio decorrem da própria scheelita-powellita e da presença relativamente comum de molibdenita.

Em ambos os tipos de escarnitos, conteúdos metálicos subordinados correspondem a disseminacões localizadas de sulfetos (calcopirita, bornita, pirita, \pm molibdenita), e carbonates supérgenos (malaquita, azurita) e ouro. Quando presentes, os teores se restringem a trechos centimétricos de escarnito, onde são medidos até $4 \%$ de Cu e $11 \mathrm{ppm}$ de $\mathrm{Au}$. O ouro é, em geral, detectado apenas por análise química, devendo estar contido na estrutura dos sulfetos. Podem, porém, ser visto na forma livre em zonas de alteração supérgena intensa.

As concentrações wollastonita eqüivalem a agregados fibroradiados milimétricos ou acículas submilimétricas a milimétricas distribuídos nos granada-wollastonita escarnitos, onde alcançam teores médios de $45 \%$. Ocorrem também bolsões ricos de wollastonita de segunda geração (?), onde o mineral atinge teores até $80 \%$. Estes bolsões são constituídos por agregados milimétricos a centimétricos, cinza-esbranquiçados, de wollastonita fibrorradiada associada à granada e à vesuvianita.

Figura 6 - Diagramas de variação de elementos maiores e silica nas fades do maciço Itaoca. 
$\mathrm{O}$ maciço possui uma reserva medida de $115000 \mathrm{t}$ de minério com teor médio de $0,3 \%$ de $\mathrm{WO}_{3}$, cerca de $850.000 \mathrm{t}$ de escarnitos com 450.000 t de wollastonita contida.

As várias ocorrências minerais podem, portanto, ser sistematizadas da seguinte forma: (1) sulfetos de cobre, molibdênio e chumbo ( \pm pirita \pm pirrotita) em veios de quartzo, (2) fluorita em veios de quartzo ou filões de greisens, (3) sulfetos de cobre e molibdênio ( \pm pirita \pm pirrotita \pm marcassita) em granitóides e milonitos derivados, e (4)

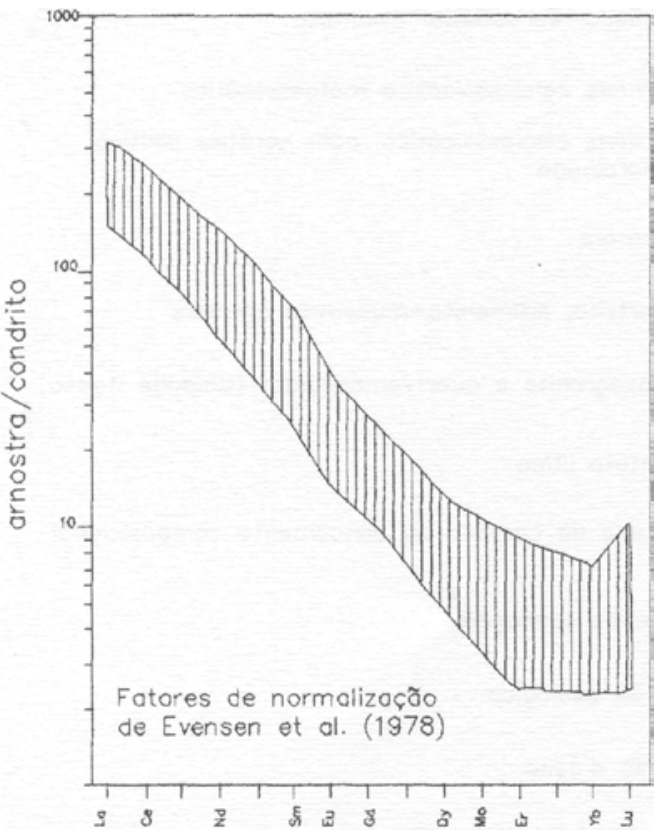

Figura 8 - Padrão da variação de elementos Terras Raras nas fades do maciço Itaoca. wollastonita e scheelita-powellita e ( \pm calcopirita \pm bornita \pm molibdenita \pm pirita \pm pirrotita \pm malaquita \pm azurita \pm ouro) em escarnitos.

IDADES Dados radiométrico em rocha total de granitóides da Unidade Saltinho (Tabela 5) forneceram uma idade $\mathrm{Rb} / \mathrm{Sr}$ de $626 \pm 27$ Ma para a fácies Rósea 2 (R.I. $=0,710-0,711)$, considerada como aproximadamente a do Maciço Itaoca.

Por outro lado, os dados radiométricos das mineralizações de fluorita em filões da zona de cisalhamento do Pavão (leste do maciço, Fig. 3), permitem especular sobre a idade do evento cisalhante. A partir do método de Ruiz et al. (1 984), a razão inicial média de 0,7114 dessas fluoritas (minerais sem $\mathrm{Rb}$ ), pode ser considerada como a razão inicial dos isótopos do elemento no sistema mineralizado, e as razões ${ }^{87} \mathrm{Rb} /{ }^{86} \mathrm{Sr}$ e ${ }^{87} \mathrm{Sr} /{ }^{86} \mathrm{Sr}$ dos granitóides hidrotermalizados encaixantes, como as composições isotópicas atuais do sistema. Isto permite calcular a idade da mineralização e do cisalhamento em $520 \pm 30 \mathrm{Ma}$ (Tassinari \& Mello 1994). Isto é compatível com o intervalo de idades admitido para os eventos de transcorrência regionais e que teriam reajustado o sistema isotópico na passagem do Proterozóico ao Fanerozóico.

Por sua vez, as idades $\mathrm{Pb} / \mathrm{Pb}$ obtidas em galena de veios de quartzo alojados em fraturas do maciço apresentam idades da ordem de 1.400 Ma (Tabela 6), que são destituídas de significado temporal, por serem mais antigas que o batólito.

O MACIÇO ITAOCA NO CONTEXTO GEOLÓGICO E EVOLUTIVO REGIONAL Com base na semelhança de litotipos, e considerando que a faixa de ocorrência do maciço Itaoca foi submetida a uma tectônica de cavalgamentos sucessivos e aloctonia das encaixantes, é possível relacionar as formações Passa Vinte e Gorutuba, do topo do Subgrupo Lajeado, com a Formação Água Clara, do embasamento desta unidade. $\mathrm{O}$ estilo tectônico permite, ainda, correlacionar as formações Betari, Água Suja e Serra da Boa Vista. Assim, o empilhamento dessas últimas unidades em horizontes estratigráficos aparentemente distintos resultaria de imbricação tectônica, o que se coaduna com a semelhança litológica e ordem estratigráfica interna descritas por Hasui et al. (1984). Estas inferências acerca das encaixantes do Maciço Itaoca constam da coluna estratigráfica da Tabela 1.

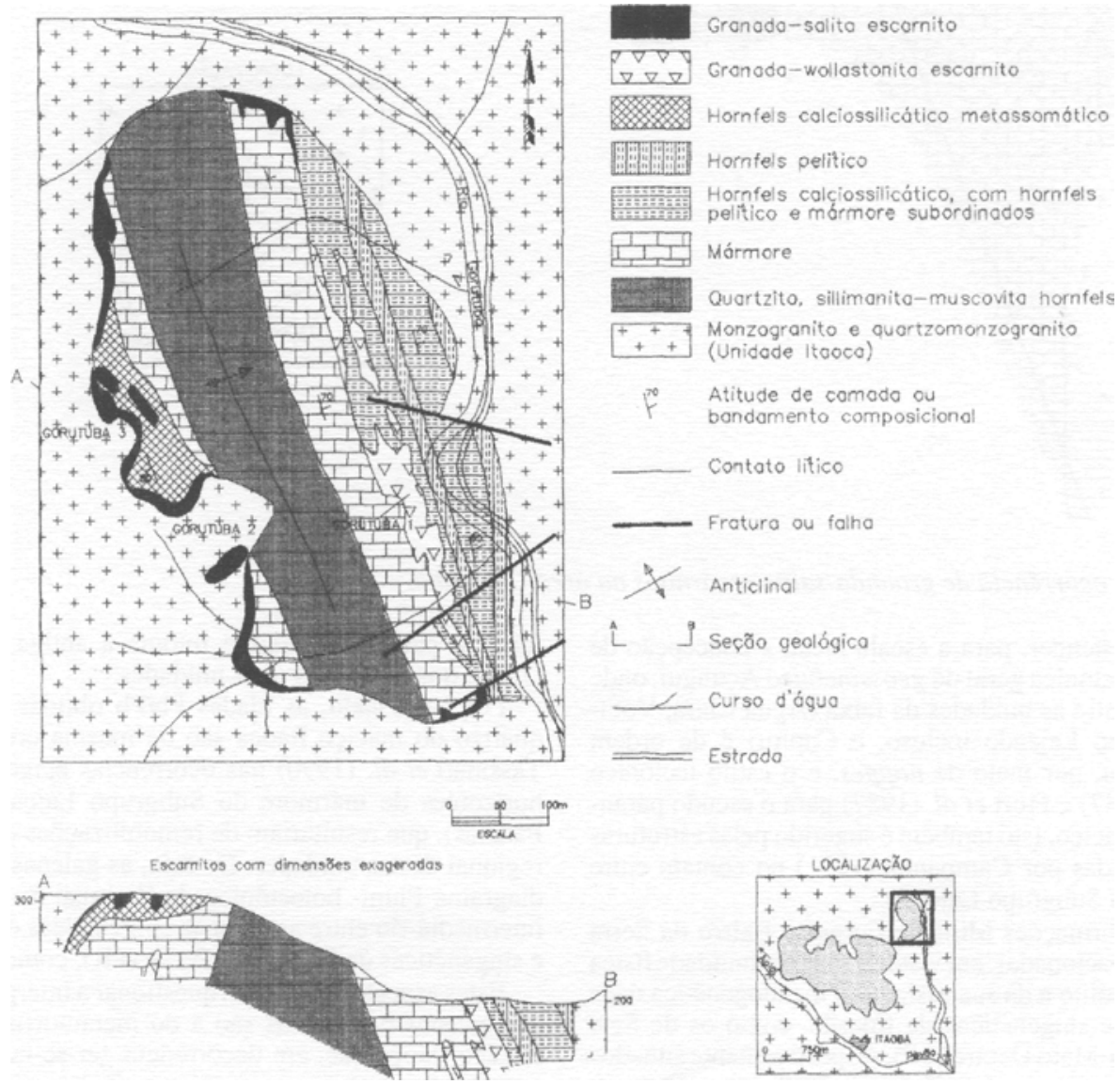

Figura 9 - Geologia da área Gorutuba, parte central do maciço Itaoca. 

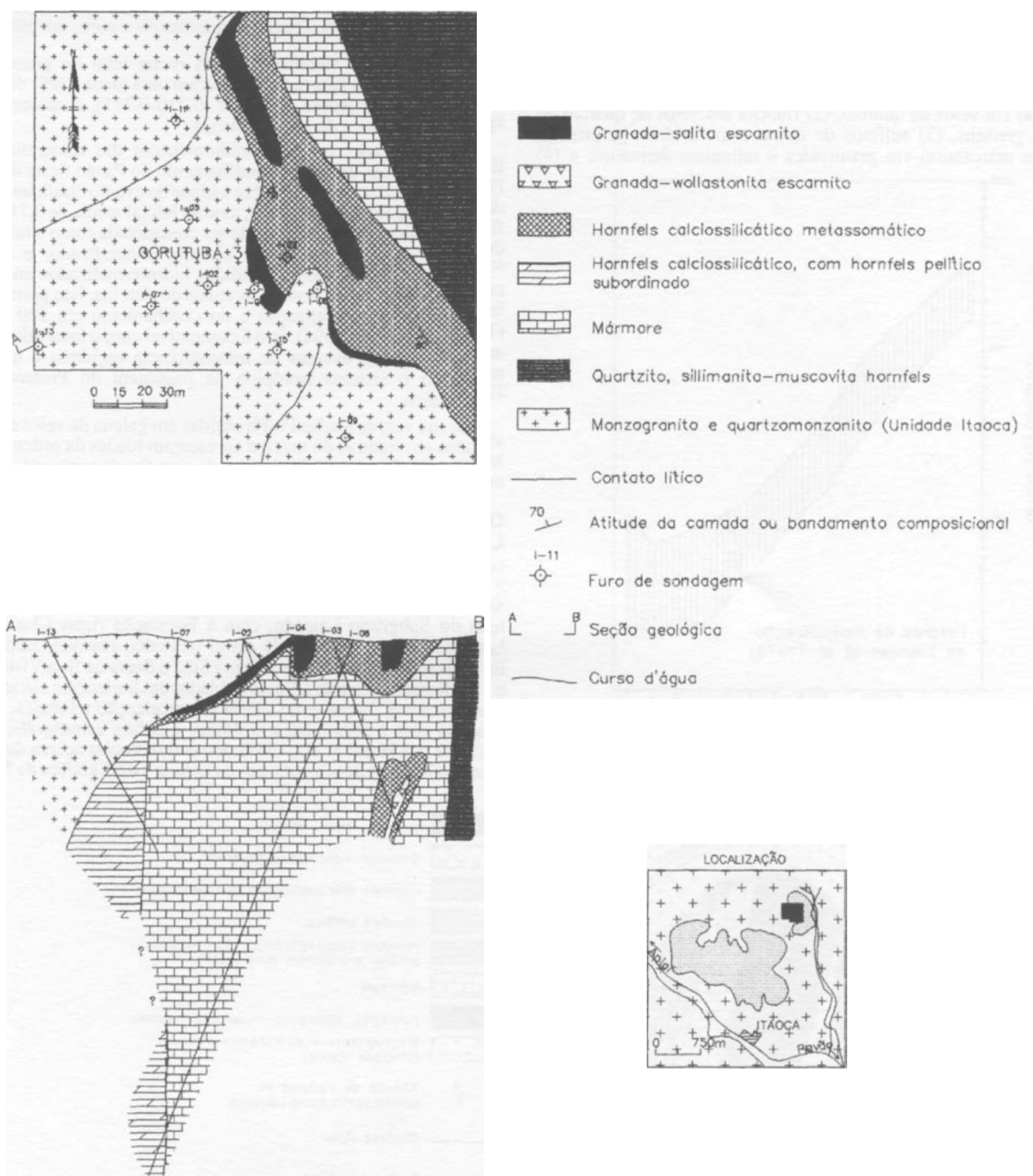

Figura 10 - Geologia da ocorrência de granada-salita escarnitos na área Gorutuba.

A hipótese permite estender, para a escala local, a concepção de Ebert (1971) acerca da tectônica geral do geossinclíneo Açungui, onde se prevê que a relação entre as unidades da faixa (Água Clara, Votuverava, com o Subgrupo Lajeado incluso, e Capiru) é de ordem essencialmente estrutural, por meio de nappes, e o estilo tectônico proposto por Soares (1987) e Fiori et al. (1987) para o escudo paranaense exposto a sul do maciço. Isto também é sugerido pelas estruturas de cavalgamento mapeadas por Campanha (1991) no contato entre algumas das unidades do Subgrupo Lajeado.

Adicionalmente, as formações Mina de Furnas e Bairro da Serra também podem ser correlacionadas, em vista de sua continuidade física na borda sudoeste do batólito e da sua assinatura metalogenética dada por depósitos similares e singenéticos de fluorita, como os de Sete Barras (PR) e de Saltinho-Mato Dentro (SP), respectivamente situados nas bordas sul e oeste do maciço. Isto já fora defendido por Campos Neto (1983b) e Pires (1990) com base em outros argumentos estru- turais e paleoambientais e retoma a antiga concepção de Barbosa (1941) quanto a estas duas unidades.

Por outro lado, as idades $\mathrm{Pb} / \mathrm{Pb}$ obtidas em galena de veios de quartzo do maciço Itaoca são de mesma ordem que as obtidas por Tassinari et al. (1990) nas ocorrências epigenéticas de chumbo dos horizontes de mármore do Subgrupo Lajeado (minas de Furnas e Panelas), que resultariam de remobilizações durante o metamorfismo regional destas unidades. De fato, as galenas do batólito ocupam, no diagrama Plum- botectônico de Zartman \& Doe (1981), um campo intermediá-rio entre as galenas epigenéticas dos depósitos de Panelas e singenéticas da Formação Perau (PR), como mostra a figura 12.

Estes aspectos permitem questionar a interpretação de que as idades das galenas de Panelas são a do metamorfismo das encaixantes do maciço Itaoca que, em decorrência, ter-se-iam depositado no Mesoproterozóico, como proposto por Tassinari et al. (1990), hipótese utilizada em alguns dos artigos que procuram interpretar a evolução 

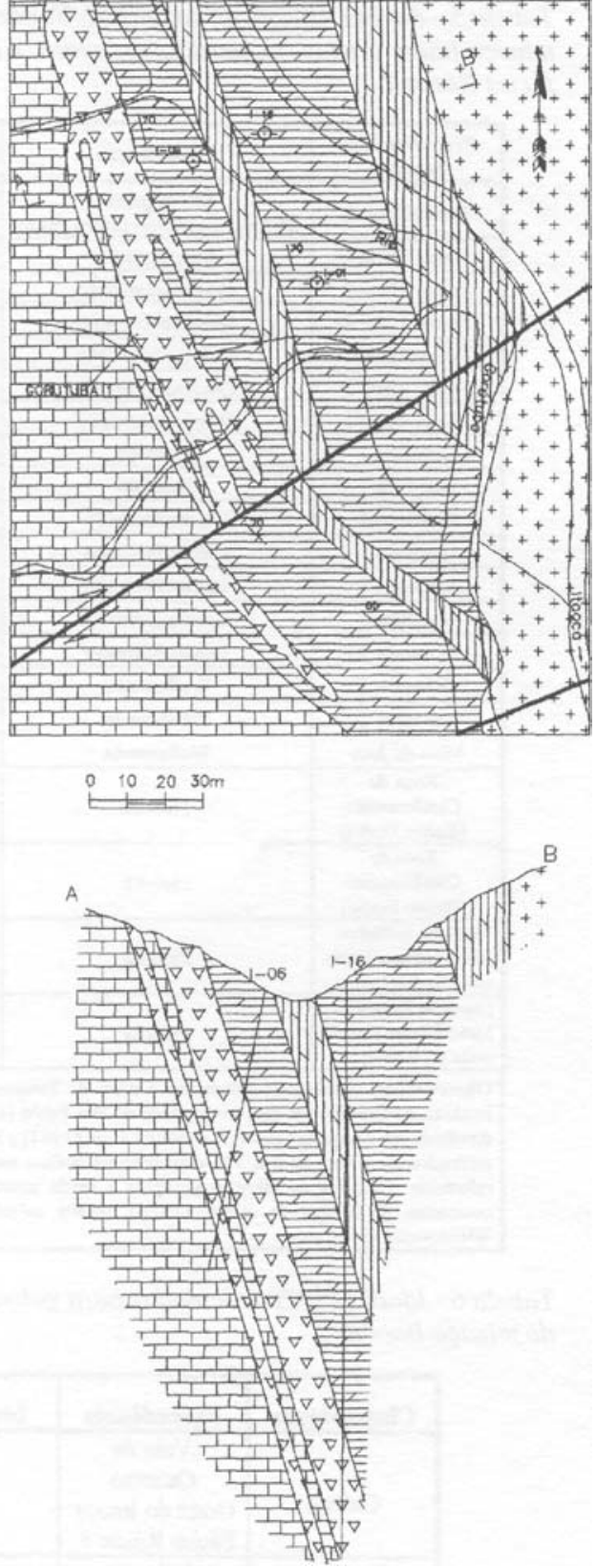

Horniels colciossilicótico, com hornfels pelitico e mórmore subordinodo

Hornfels pelitico

Mórmore

Monzogranitos e quartzomonzogranitos (Unidode Itooco)

Contoto litico

70 Atitude de camada ou bandamento composicional

- Fratura

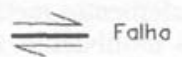

Furo de sondagem

A I Seçชo geológico

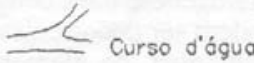

Estrodo e cominho

Lochuzação

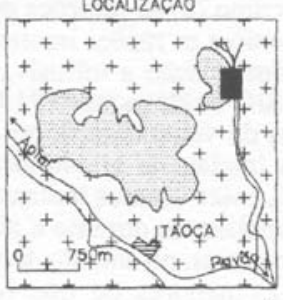

Figura 11 - Geologia da ocorrência de granada-wollastonita escarnitos na área Gorutuba.

geológica do Vale do Ribeira (Campanha 1991, Gimenez Filho 1993, Poidevin et al 1997).

De modo alternativo, é possível considerar que as mineralizações epigenéticas de chumbo do Vale do Ribeira, localizadas nos mármores do Subgrupo Lajeado, sejam mais jovens do que indicado pelos dados geocronológicos. Neste caso, esta resultariam de remobilizacões, durante o Neoproterozóico (Brasili-ano), das mineralizações tipo Perau, datadas em cerca de $1.700 \mathrm{Ma}$ (Tassinari et al. 1990). Assim, por razões a ser investigadas, as datações das mineralizações epigenéticas, indepen-dente da natureza das encaixantes (ver o caso do maciço Itaoca), estariam registrando valores intermediários entre a idade das mineralizações primárias (Perau), e a da remobilização brasiliana.

Esta hipótese também é uma alternativa para compreender a origem dos depósitos tipo Panelas, já que estes, pelo menos sua ambiência (poderia se alegar que as demais características teriam sido mascaradas por metamorfismo regional), parecem não se enquadrar nos modelos clássicos de depósitos sedimentares de chumbo em rochas carbonáticas, seja do tipo Mississipi Valley, ou do tipo Irlanda, como descritos, por exemplo, por Badham (1981).

Os argumentos apresentados e a correlação da evolução geológica do Vale do Ribeira com modelos postulados para regiões adjacentes (i. e. Giuliani 1993J permitem interpretar o maciço Itaoca como uma

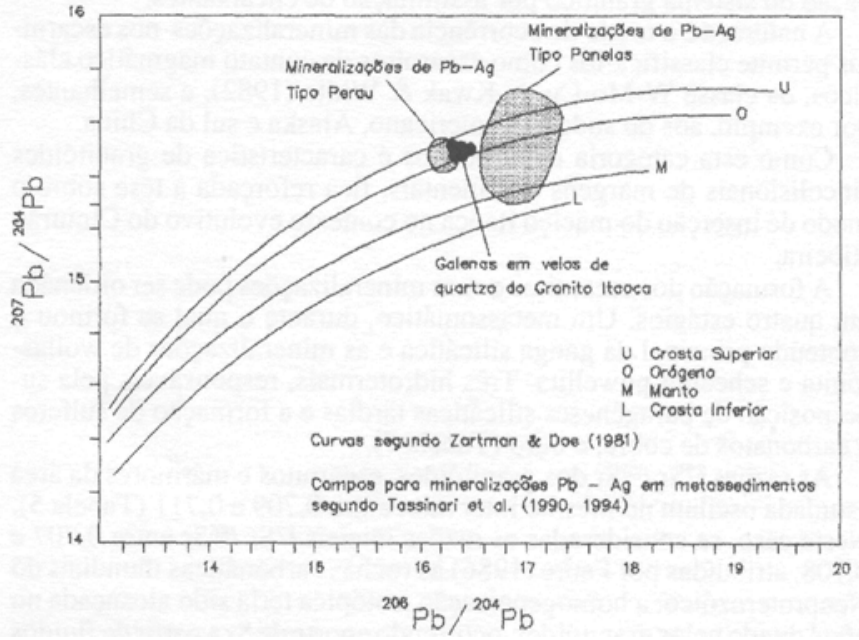

Figura 12 - Distribuição de razões isotópicas de chumbo nas galenas de veios de quartzo do maciço Itaoca e das minas do Perau e Panelas em diagrama de plumbotectônica. 
intrusão tardia em relação ao arco magmático tipo andino, possivelmente representado pelos complexos granitóides Cunhaporanga, Três Córregos e Agudos Grandes, durante o fechamento da Bacia Açungui no Brasiliano. Isto possibilita correlacionar o maciço Itaoca com outras intrusões da região, tais como os granitos porfiróides descritos por Gimenez Filho na área do Complexo Granitóide Três Córregos. A partir disto, modelos de evolução regional como os propostos por Soares $(1987,1988)$ passam a ser referências importantes, comojáfora o de Soares (1988) para Wernick (1990), no estudo do zoneamento magmático do Sul e Sudeste do Brasil.

Outra hipótese para o entendimento da evolução do maciço Itaoca e da sua inserção no contexto geológico regional, seria considerá-lo como uma manifestação magmática associada às zonas de cisalhamento transcorrente que o ladeiam, os lineamentos Quarenta-Oitava e Ribeira, à semelhança da concepção de Ebert et al. (1984) e Hacksparker \& Godoy (1995), para gênese de intrusões granitóides em situação similar, em outros setores do pré-cambriano paulista. No momento, no entanto, não há argumentos que sustentem esta alternativa, e há aspectos conflitantes, como a idade do maciço, mais antiga que o evento dínamotermal, o que dificulta correlacionar a geração do maciço com regimes transtensivos ou transpressivos da transcorrência neoproterozóica do Cinturão Ribeira, a menos que se admita sucessivas reativações dessas zonas transcorrentes, desde épocas mais antigas.

MODELOS METALOGENÉTICOS Dentre os elementos metálicos das mineralizações hidrotermais, o cobre e o molibdênio são compatíveis com a natureza do maciço Itaoca (i. e. Kequin et al. 1984), o que sugere que tenham sido concentrados a partir de soluções residuais durante alterações tardi após-magmáticos (disseminações de Mo-Cu nas Fácies Cinza 3), ou remobilizados dos granitóides durante eventos dínamotermais superimpostos $(\mathrm{Cu}$ em brechas, zonas de cisaIhamento e granitóides milonitizados).

Já o $\mathrm{Pb}$ e o F são elementos estranhos à metalogênese mais comum a este tipo de maciço. Estas mineralizações podem ser decorrentes da migração, para zonas permeáveis da área plutônica, de elementos carreados a partir das encaixantes por conveccão durante eventos dínamotermais, como modelados por Plant et al. (1 983). A hipótese da participação de material das encaixantes no processo de mineralização é reforçada pela existência de depósitos de fluorita e chumbo nas rochas regionais (galena epigenética e fluorita singenética nos mármores da Formação Mina de Furnas), e pelos indícios de contaminação do maciço por digestão das encaixantes, tais como (a) as relações de campo, (b) os teores elevados de flúor e alumínio e as razões iniciais ${ }^{86} \mathrm{Sr} /{ }^{87} \mathrm{Sr}$ aumentadas nas fácies granitóides em relação a intrusivas Tipo / (Tabelas 3 e 5), e (c) as razões iniciais ${ }^{86} \mathrm{Sr} /{ }^{87} \mathrm{Sr}$ elevadas $(0,719)$ nos granitóides hidrotermalizados encaixantes de veios com fluorita (Bairro Pavão). Sendo maiores que as razões iniciais de granitóides não alterados da Unidade Itaoca $(0,710-0,711)$, esses últimos indicam a participação de fluidos provenientes das encaixantes durante a alteração daquelas rochas. A fluorita destas ocorrências, no entanto, têm razões iniciais ${ }^{86} \mathrm{Sr} /{ }^{87} \mathrm{Sr}$ entre 0,711 e 0,712 , menores do que os granitóides alterados e a fluorita singenética da borda ígnea $(0,714)$, indicando que não ocorreu transferência de flúor diretamente das rochas regionais para a zona de cisalhamento e conseqüente contaminação do sistema granítico por assimilação de encaixantes.

A natureza e o modo de ocorrência das mineralizações nos escarnitos permite classificá-los como escarnitos de contato magmático clássicos, da classe W-Mo-Cu de Kwak \& White (1982), e semelhantes, por exemplo, aos do sudoeste americano, Alaska e sul da China.

Como esta categoria de depósitos é característica de granitóides sincolisionais de margens continentais, fica reforçada a tese sobre o modo de inserção do maciço Itaoca no contexto evolutivo do Cinturão Ribeira.

A formação dos escarnitos e suas mineralizações pode ser ordenada em quatro estágios. Um metassomático, durante o qual se formou o conteúdo principal da ganga silicática e as mineralizações de wollastonita e scheelita-powellita. Três hidrotermais, responsáveis pela superposição de paragêneses silicáticas tardias e a formação de sulfetos e carbonates de cobre, e ouro (Tabela 7).

As razões ${ }^{87} \mathrm{Sr} /{ }^{86} \mathrm{Sr}$ dos granitóides, escarnitos e mármores da área estudada oscilam no mesmo intervalo, entre 0,709 e 0,711 (Tabela 5). Neste caso, se consideradas as razões iniciais ${ }^{87} \mathrm{Sr} /{ }^{86} \mathrm{Sr}$ entre 0,707 e 0,708, atribuídas por Faure (1986) às rochas carbonáticas mundiais do Neoproterozóico, a homogeneização isotópica teria sido alcançada no nível ditado pelos granitóides, ocorrendo aporte de Sr a partir de fluidos provenientes das intrusões. Mecanismo semelhante foi verificado mediante estudos isotópicos sistemáticos em exemplos de escarnitos de contato com W do Japão (Nakano et al. 1990).
Tabela 5 - Razões isotópicas iniciais Rb/Srpara minerais e rochas do maciço Itaoca e suas encaixantes próximas, e idade calculada para a fácies Rósea 2.

\begin{tabular}{|c|c|c|}
\hline $\begin{array}{l}\text { Procediancla da } \\
\text { Amoetra }\end{array}$ & Chunificacto & $\begin{array}{l}\text { Idade (Ma) e/on } \\
\text { Rexto Intel }\end{array}$ \\
\hline Fúcies Cinza 1 & $\begin{array}{c}\text { Monzogranito } \\
\text { (Hidrotermalizado - Bairo Pavão) }\end{array}$ & $0,71922 \pm 0,00014$ \\
\hline Fácies Cinza 3 & Monzogranito & $0,71090 \pm 0,00052$ \\
\hline Fúcies Rósea 2 & Quartzomonzonito & \multirow{5}{*}{$\begin{array}{c}626 \pm 27 \\
0,70997 \pm 0,00016 \\
(\mathrm{MSWD}=3,914)\end{array}$} \\
\hline Fácies Rosea 2 & Quartzomonzonito & \\
\hline Fúcies Rórea 2 & Quartzomonzonito & \\
\hline Fúcies Rósea 2 & Quartzomonzonito & \\
\hline Fácies Rósea 2 & Quartzomonzonito & \\
\hline Gorutuba 1 & Escamito & $0,71101 \pm 0,00006$ \\
\hline Gorutuba 1 & Escamito & $0,71083 \pm 0,00008$ \\
\hline Gorutuba 1 & Calcita/Escamito & $0,71028 \pm 0,00012$ \\
\hline Gorutuba 1 & Calcita/Escamito & $0,71099 \pm 0,00011$ \\
\hline Gorutuba 1 & Calcita/Escamito & $0,71037 \pm 0,00006$ \\
\hline Gorutuba 1 & Calcita/Mámore & $0,71004 \pm 0,00006$ \\
\hline Gontube 1 & Calcita/Marmore & $0,71071 \pm 0,00009$ \\
\hline Gorutuba 1 & Wollastonita & $0,70931 \pm 0,00006$ \\
\hline Gonutuba 1 & Wollastonita & $0,70921 \pm 0,00006$ \\
\hline Mina do Juca & Wollastonita & $0,70926 \pm 0,00008$ \\
\hline $\begin{array}{c}\text { Zona de } \\
\text { Cisalhamento } \\
\text { (Bairro Pavalo) }\end{array}$ & Fhuorita & $0,71156 \pm 0,00013$ \\
\hline $\begin{array}{c}\text { Zona de } \\
\text { Cisalhamento } \\
\text { (Bairno Pavao) }\end{array}$ & Fluorita & $0,71120 \pm 0,00008$ \\
\hline $\begin{array}{l}\text { Depdrito Satinho- } \\
\text { Mato-Dentro (borda } \\
\text { oeste do Kaoca) }\end{array}$ & Fluorita & $0,71414 \pm 0,00011$ \\
\hline $\begin{array}{l}\text { Deposito Sallinho- } \\
\text { Mato-Dentro (borda } \\
\text { oeste do flacas) }\end{array}$ & Fluorita & $0,71460 \pm 0,00005$ \\
\hline \multicolumn{3}{|c|}{ 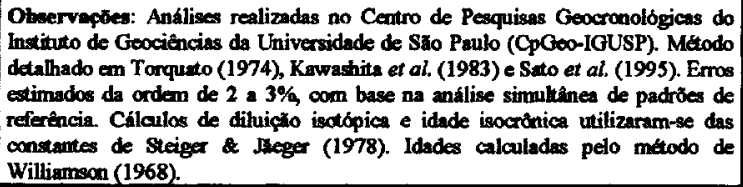 } \\
\hline
\end{tabular}

Tabela 6 - Idades $\mathrm{Pb} / \mathrm{Pb}$ calculadas para galenas em veios de quartzo do maciço Itaoca.

\begin{tabular}{|c|c|c|}
\hline Clowiferepio & Procedencia & Idede (Ma) \\
\hline Galena & $\begin{array}{c}\text { Veio de } \\
\text { Quartzo } \\
\text { Oeste do lisoca } \\
\text { Fácies Rósea } 3\end{array}$ & 1.446 \\
\hline Galena & $\begin{array}{c}\text { Veio de } \\
\text { Quartzo } \\
\text { Oeste do Itaoca } \\
\text { Fácies Rósea } 3\end{array}$ & 1.425 \\
\hline Galena & $\begin{array}{c}\text { Veio de } \\
\text { Quartzo } \\
\text { Lecte do Itaoca } \\
\text { Fácies Cinza } 1\end{array}$ & 1.497 \\
\hline Galena & $\begin{array}{c}\text { Veio de } \\
\text { Quartzo } \\
\text { Oeste do ftaoca } \\
\text { Fácies Rósea } 3\end{array}$ & 1.422 \\
\hline Galena & $\begin{array}{c}\text { Veio de } \\
\text { Quartzo } \\
\text { Oeste do Haoca } \\
\text { Fácies Rósea } 3\end{array}$ & 1.422 \\
\hline \multicolumn{3}{|c|}{$\begin{array}{l}\text { Observacues: Análises realizadas no Centro de } \\
\text { Pesquisas Geocronológicas do Instinto de } \\
\text { Geaciâncias da Universidade de Sto Paulo (CpGeo- } \\
\text { lGUSP). Análise espectométrica detallhada em } \\
\text { Sato et al. (1995). Precisa analítica aferida por } \\
\text { padröes internacionais, conforme descrito por. } \\
\text { Tassinari et al. (1990), com erros da ordem de } \\
0,01 \% \text {. Idades calculadas com base no modelo de } \\
\text { Stacey \& Kramers (1975). }\end{array}$} \\
\hline
\end{tabular}




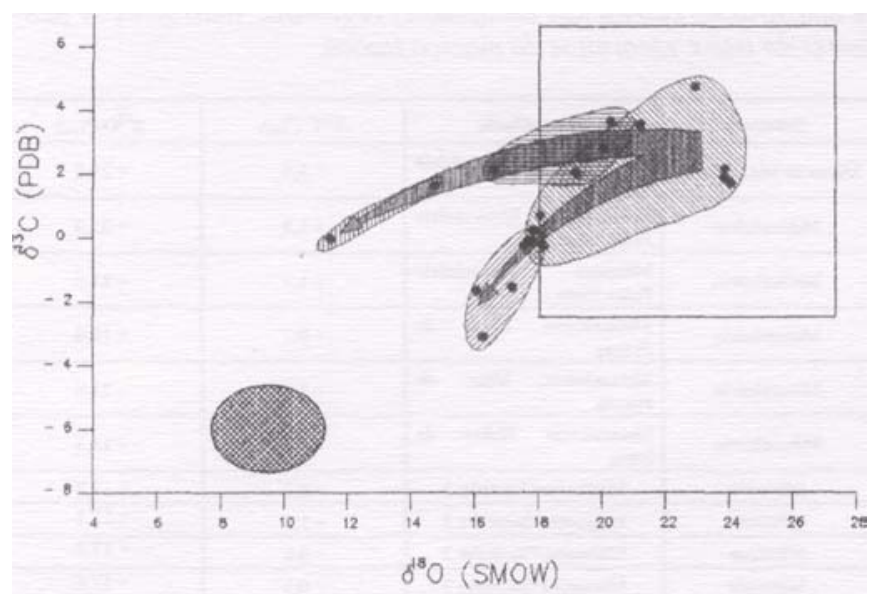

Metocolearios regionals

Mórmores encaixantes do Gorutubo 1

Mórmores encaixantes do Gorutubo 3

[ini Celcitos tordios (Gorutubo 1)

Compo paro solcites e doiomitos mundiais do

Neso a Neoproterozólco ( Veizer \& Hoets 1976)

Campo de referêncio pora "caleitos magmáticos"

(Brown et at. 1885, volley of of 1985)

Figura 13 - Campos de variação $\delta^{13} \mathrm{C}$ e $\delta^{18} O$, e linhagens de racionamento isotópico de carbono e oxigênio de calcita das encaixantes metacalcárias, mármores de pendentes do teto e escarnitos do maciçoItaoca.
Por outro lado, as Tabelas 8 e 9 mostram, respectivamente, os resultados analíticos de isótopos de carbono e oxigênio em rochas e calcitas das encaixantes metacalcárias da borda do batólito, mármores e escarnitos do maciço Itaoca, e isótopos de oxigênio em silicates dos escarnitos da área. A Figura 13 exibe os campos de variação ô ${ }^{13} \mathrm{C}$ e ô

${ }^{18} \mathrm{O}$ nas amostras analisadas. Na figura, também constam o campo de variação isotópica de carbono e oxigênio em rochas carbonáticas do Meso e Neoproterozóico definido por Veizer \& Hoefs (1976), e o campo de variação de calcitas magmáticas, equivalente à composição isotópica teórica de calcitas em equilíbrio, a $600^{\circ} \mathrm{C}$, com magmas calci-alcalinos formadores dos escarnitos de Pine Creek, EUA (Brown et al 1985) e à de calcitas primárias de granitos analisados por Deines \& Gold (1969) na região de Montreal, Canadá. Também foi incluído o resultado de uma análise realizada por Bettencourt et al. (1992) em metacalcário da Formação Mina de Furnas, compatível com os resultados aqui obtidos em amostras de metacalcários da borda do maciço.

Os resultados mostram que há dois trends de fracionamento isotópico. Um relacionado aos protólitos metacalcários da borda do macico, mármores associados aos granada-wollastonita escarnitos da área Gorutuba (corpo Gorutuba 1, Figuras 9 e 11) e às calcitas tardias dos escarnitos. Outro relacionado às encaixantes e aos mármores dos granada-salita escarnitos (corpos Gorutuba 2 e 3, Figuras 9 e 10).Este se distingue do primeiro por um fracionamento maior, com valores menores nos escarnitos. Ambas as rotas de fracionamento estão afastadas do campo das calcitas magmáticas, embora evoluam no mesmo sentido.

Considerando as características geológicas da área Gorutuba, é possível supor que o principal condicionante da diferença de fracionamento entre os dois trends seja a distância ao contato ígneo, maior nos mármores do Gorutuba 1 que nos do Gorutuba 3.

Assim, no maciço Itaoca, parece repetir-se o padrão observado em auréolas de contato granitóide, caracterizadas pelo maior empobrecimento em $\delta^{13} \mathrm{C}$ e $\delta^{18} \mathrm{O}$ à medida em que aumenta a ação térmica da intrusão (Valley et al 1986), a partir de processos diferenciados de volatilização (descarbonatação, desidratacão), infiltração e mistura de fluidos, e desequilíbrios nas condições de pressão e temperatura durante a evolução do metamorfismo de contato (i.e. Layne et al 1991, Valley et al 1986).

Tabela 7 - Estágios deformação das paragêneses e mineralizações dos escarnitos do maciço Itaoca.

\begin{tabular}{|c|c|c|c|c|c|c|}
\hline \multirow{2}{*}{\multicolumn{2}{|c|}{ Estágio }} & \multirow{2}{*}{$\begin{array}{c}\text { Magmático } \\
1\left(>650-600^{\circ} \mathrm{C}\right)\end{array}$} & \multirow{2}{*}{$\begin{array}{l}\text { Metassomático } \\
2\left(600-550^{\circ} \mathrm{C}\right)\end{array}$} & \multicolumn{2}{|c|}{ Hidrotermal Hipogênico } & \multirow{2}{*}{$\begin{array}{c}\text { Hidrotermal Supergênico } \\
\qquad \mathbf{5}\left(<80^{\circ} \mathrm{C} \text { ?) }\right.\end{array}$} \\
\hline & & & & $3\left(550-450^{\circ} \mathrm{C}\right)$ & $4\left(450-80^{\circ} \mathrm{C} ?\right)$ & \\
\hline \multicolumn{2}{|c|}{ Eventos } & $\begin{array}{l}\text { Metamorfismo iso- } \\
\text { quimico de contato } \\
\text { (desenvolvimento de } \\
\text { homfels, recrista- } \\
\text { lizaça de már- } \\
\text { mores) }\end{array}$ & $\begin{array}{l}\text { Bimetassomatismo (difusão } \\
\text { iônica) de contato (Fe, } \mathrm{Mg} \text {, Si e } \\
\text { Al para os mármores, Ca para } \\
\text { os granitóides). Formação de } \\
\text { endo e exoescarnitos, e hornfels } \\
\text { metassomáticos. Retrometa- } \\
\text { morfismo nos homfels e } \\
\text { mármores. Mineralização de } \\
\text { scheelita-powellita e wollasto- } \\
\text { nita. Injeģa de diques } \\
\text { granitóides tardios albitizados. }\end{array}$ & \multicolumn{2}{|c|}{$\begin{array}{l}\text { Retrometamorfismo nos escamitos. } \\
\text { Mineralizaçües de sulftos metálicos. }\end{array}$} & $\begin{array}{l}\text { Afteraçées das minerali- } \\
\text { zaçües metálicas. }\end{array}$ \\
\hline \multicolumn{2}{|c|}{ Mármore } & $\begin{array}{l}\text { calcita + diopsidio } \pm \\
\text { quartzo }\end{array}$ & & $\begin{array}{l}\text { tremolita } \pm \\
\text { flogopita }\end{array}$ & & \\
\hline \multirow[t]{2}{*}{ Escarnito } & $\begin{array}{c}\text { Tipo } \\
\text { Gorutuba } 3\end{array}$ & & $\begin{array}{l}\text { salita + granada } 1 \text { (andradita- } \\
\text { glossulária) }\end{array}$ & $\begin{array}{l}\text { granada } 2 \text { (andra- } \\
\text { dita-grossulária) } \pm \\
\text { pirita } 1 \text { (?) } \pm \text { mag- } \\
\text { netita } \pm \text { quartzo }\end{array}$ & $\begin{array}{l}\text { epidoto } \pm \text { albita } \pm \\
\text { actinolita } \pm \text { calcita } \\
\pm \text { pirita } 1 \pm \text { esfa- } \\
\text { lerita } \pm \text { arsenopi- } \\
\text { rita } \pm \text { pirrotita } \pm \\
\text { caloopirita }\end{array}$ & pirita $2+$ marcassita \\
\hline & $\begin{array}{c}\text { Tipo } \\
\text { Gorutuba 1 }\end{array}$ & & $\begin{array}{l}\text { wollastonita } 1+\text { granada } 1 \\
\text { (grossulária-andradita) }+ \text { diop- } \\
\text { sidio } \pm \text { scheelita-powellita }\end{array}$ & $\begin{array}{l}\text { wollastonita } 2(?)+ \\
\text { granada } 1 \text { (gros- } \\
\text { sulária-andradita)+ } \\
\text { granada 2 (gros- } \\
\text { sulária-andradita) }\end{array}$ & $\begin{array}{l}\text { vesuvianita } \pm \text { albi- } \\
\text { ta } \pm \text { albita } \pm \text { calcita } \\
\pm \text { quartzo } \pm \text { apofi- } \\
\text { lita } \pm \text { prehnita } \pm \\
\text { pirita } \pm \text { calcopirita } \\
\pm \text { bornita } \pm \text { cove- } \\
\text { lita } \pm \text { calcocita }\end{array}$ & $\begin{array}{l}\text { malaquita } \pm \text { azurita } \pm \text { hidró- } \\
\text { xidos ferruginosos } \pm \text { ouro }\end{array}$ \\
\hline
\end{tabular}


$\mathrm{O}$ fracionamento diferenciado entre os tipos de escarnito e a dispersão de valores $\delta^{13} \mathrm{C}$ e $\delta^{18} \mathrm{O}$ não evidenciam equilíbrio de fluídos nos sistemas granitóide-mármore-escarnito, o que poderá ter ocorrido apenas localmente ao longo das linhagens isotópicas individuais, como sugerem alguns resultados próximos registrados nos mármores do Gorutuba 3. Isto também é indicado por valores uniformes de $\delta^{18} \mathrm{O}$ em alguns silicatos (Tabela 9).

$\mathrm{O}$ afastamento dos extremos isotópicos mais empobrecidos em relação ao campo da calcita magmática sugere a forte predominância, durante o metassomatismo que gerou os escarnitos estudados, de água metamórfica proveniente do pacote metassedimentar. O empobrecimento isotópico em relação ao campo ígneo, no entanto, sugere também a participação, mas subordinada, de água magmática no processo, o que se coaduna com a hipótese de homogeneização isotópica de estrôncio no sistema em nível ditado pelas intrusivas. Em Pine Creek (EUA), o decréscimo de $\delta^{13} \mathrm{C}$ e $\delta^{18} \mathrm{O}$ nos escarnitos em relação aos protólitos metacalcários, é atribuído a um processo semelhante (Valley et al. 1986).

Água meteóricas parecem não ter participado das fases ígnea, metassomática e hidrotermal de formação dos escarnitos, em vista dos elevados valores de $\delta^{18} \mathrm{O}$ nos carbonates analisados. Contudo, a sua presença não pode ser descartada, antes da obtenção e da avaliação de dados isotópicos de deutério $(\delta \mathrm{D})$ em silicatos hidratados do sistema mármore-escarnito.

A questão da fonte dos elementos metálicos concentrados em escarnitos de contato magmático é, em geral, complexa (Einaudi et al. 1981, Kwak 1987). No caso estudado, supõem-se que os granitóides podem ser a fonte principal de $\mathrm{W}$, Mo e $\mathrm{Cu}$ dos escarnitos. Isto é indicado pela (a) coincidência entre a natureza do batólito, sua vocação metalogenética e o tipo de mineralizações metálicas dos escarnitos, a partir de modelos como os de Einaudi et al (1981), Kwak \& White (1982), Kequin et al. (1984) e Kwak (1987); (b) a aparente ausência, na região, de rochas ricas em $\mathrm{W}$ ou mesmo de depósitos, vulcanossedimentares do elemento; (c) a capacidade mineralizante do maciço em relação ao cobre e molibdênio em metassomatitos e milonitos, e (d) embora não conclusiva, a possível participação de fluidos magmáticos na formação dos escarnitos da área, sugerida pelos dados isotópicos.

Este modelo metalogenético viabiliza a existência de depósitos disseminados de $\mathrm{Mo} \mathrm{e} \mathrm{Cu}$ em cúpulas não erodidas de granitóides e concentrações de $\mathrm{W}$ em greisens, sob as raízes dos pendentes do teto.

Já a formação da wollastonita $\left(\mathrm{CaSiO}_{3}\right)$ é tipicamente resultante de descarbonatação dos mármores matrizes dos escarnitos da área. O mineral forma-se mediante a reação:

\section{calcita + quartzo $=$ wollastonita $+\mathrm{CO}_{2}$}

A uma pressão da ordem de 2 kbar durante a formação dos escarnitos, com $\mathrm{CO}_{2}$ na fase fluida em torno de $0,5 \mathrm{Kbar}$, como estimado por Ens (1990) durante a fase inicial do processo metassomático (Estágio 2 da Tabela 7) a wollastonita deve ter se formado a uma temperatura da ordem de $600^{\circ} \mathrm{C}$, compatível com a estabilidade do mineral (Winkler 1977).

Mantidos os demais fatores, a formação da wollastonita é favorecida pela diminuição da $f \mathrm{CO}_{2}$ na fase fluida (Winkler 1977). Deste modo, seja por aumento da quantidade de $\mathrm{H}_{2} \mathrm{O}$ volátil, seja pelo escape de $f \mathrm{CO}_{2}$, poderiam ser criadas condições mais propícias à formação do mineral, ainda que localizadas. Na área estudada, a associação de corpos mais ricos em wollastonita com fraturas ou zonas de falha sugere que a formação do mineral também foi favorecida pela diminuição da $f \mathrm{CO}_{2}$. A ocorrência de bolsões de wollastonita maciça estaria associada a um segundo estágio de geração mineral (wollastonita 2), o que explicaria, também, a presença de veios de wollastonita em fraturas dos escarnitos com wollastonita mais comuns.

Por outro lado, uma vez que os pendentes do teto com escarnitos são semelhantes a uma parte da coluna estratigráfica das rochas metassedimentares da borda do maciço, é possível correlacionar os hornfelses calcissilicáticos, pelíticos, mármores e hornfelses básicos com as rochas das formações Passa Vinte, Gorutuba e o Gabro de Apiaí, aflorantes a norte do plúton.

Considerando, além disso, que as formações Passa Vinte e Gorutuba foram correlacionadas à Formação Água Clara, pode-se formular um modelo hipotético para a formação dos escarnitos do Vale do Ribeira.

Assim, postula-se que as seqüências calcissilicáticas e os mármores da Formação Água Clara sejam os horizontes determinantes para a formação dos escarnitos e, portanto, guias para a prospecção desses corpos. Em pelo menos dois locais, um no contato com o granitóide São Sebastião, na barra do rio Açungui (PR) e outro no Santa Blandina,
Tabela 8 - Resultados das análises isotópicas de carbono e oxigênio de amostras de calcita das encaixantes regionais, mármores de pendentes do teto e escarnitos do maciço Itaoca.

\begin{tabular}{|c|c|c|c|}
\hline Neturea & Procedlanete & ${ }^{8+1} \mathrm{C}(/ \omega)$ & $8^{14} 0(\%)$ \\
\hline Marmore/Matecalatrio & $\begin{array}{l}\text { Marmored Metwalctrio } \\
\text { Pesse Vinle }\end{array}$ & $+3,5$ & $+21,2$ \\
\hline Metucalcirio & $\begin{array}{l}\text { Marmored Mctacalctio } \\
\text { Passa Vule }\end{array}$ & $+1,8$ & $+23,9$ \\
\hline Matocalctio & $\begin{array}{l}\text { Marmone' Motscalchio } \\
\text { Passa Vinde }\end{array}$ & $+1,7$ & $+24,0$ \\
\hline Metacalcirio & $\begin{array}{l}\text { Metacalctrio Ming de } \\
\text { Furnes }\end{array}$ & $+0,7$ & $+18,0$ \\
\hline Metacalcsirio & $\begin{array}{l}\text { Metacalcirio Mina de } \\
\text { Fumbs }\end{array}$ & $+2,1$ & $+23,8$ \\
\hline Metecalcário & $\begin{array}{l}\text { Metscalchio Buiro da } \\
\text { Serre }\end{array}$ & $-0,3$ & $+18,1$ \\
\hline Mirmore & Mirmores/Gorutubn 3 & $-0,1$ & $+17,7$ \\
\hline Mímore & Mérmorew/Grorutrulbu 3 & $-1,5$ & $+17,1$ \\
\hline Mímore & Mirmones/Contubla 3 & $-0,2$ & $+17,5$ \\
\hline Mérmore & Marmorea/Gorutube 3 & +02 & $+17,8$ \\
\hline Marmore & Marmorea/Qrorutubu 3 & $-0,6$ & $+16,0$ \\
\hline Mhimore & Mirmored/Gorutube 3 & $-3,1$ & $+16,2$ \\
\hline Mirmore & Mirnored/Gontuba 1 & $+3,6$ & $+20,2$ \\
\hline Minmore & Mismone/Oontube 1 & $+2,0$ & $+19,1$ \\
\hline Mirmore & Mhrmorea/Gontuba 1 & $+2,2$ & $+16,5$ \\
\hline Mimpore & Mirmored/Oonutuba 1 & $+2,8$ & $+20,0$ \\
\hline Calkits & Veios terdiog/Gontube 1 & $+0,0$ & $+11,4$ \\
\hline Calcita & Veios tandiog/Gortuba 1 & $+1,6$ & $+14,7$ \\
\hline \multicolumn{4}{|c|}{ 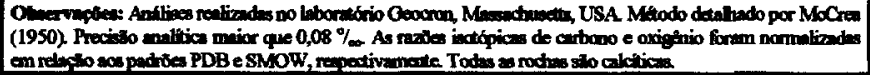 } \\
\hline
\end{tabular}

Tabela 9 - Resultados das análises isotópicas de oxigênio em silicatos dos escarnitos do maciço Itaoca.

\begin{tabular}{|c|c|c|}
\hline Naterreata & Procedîncia & $8^{110} 0$ \\
\hline Salita & Escamito Gontuba 3 & $+10,1$ \\
\hline Salita & Escamito Gorutuba 3 & $+10,5$ \\
\hline Salita & Escarnito Gorutuba 3 & $+11,4$ \\
\hline Granada & Escamito Gorrtube 3 & $+8,9$ \\
\hline Granada & Escamito Gorutuba 1 & $+8,5$ \\
\hline Granada & Escarnito Gorutuba 1 & $+8,1$ \\
\hline Wollastonita (fina) & Escamito Gorutuba 1 & $+8,6$ \\
\hline Wollastonita (grossa) & Escamito Mina do Juca & $+9,6$ \\
\hline Wollastonita (erossa) & Escamito Mina do Juca & $\begin{array}{r}+9,9 \\
\end{array}$ \\
\hline
\end{tabular}

na região de Itapeva (SP) ocorrem escarnitos em seqüências calcissilicáticas e mármores atribuídos à Formação Água Clara. Em ambos os casos, os escarnitos são idênticos, em constituição e mineralização cuprífera, aos dos pendentes de teto em Itaoca. Isto condiz com a ausência de escarnitos no contato do maciço Itaoca com metacalcários das formações Bairro da Serra e Minas de Furnas.

Em vista disto, conclui-se que os escarnitos do Vale do Ribeira são corpos stratabound associados com mármores e rochas calcissilicáticas da Formação Água Clara, embora a concentração de seus principais conteúdos metálicos possivelmente estejam subordinados à especialização dos granitóides com os quais façam contato.

Agradecimentos À Fundação de Auxílio à Pesquisa do Estado de São Paulo -FAPESP pelo auxílio financeiro aos trabalhos de campo e análises geoquímicas (Projeto 89/3.823-7). À Agência Financiadora de Estudos e Projetos - FINEP pelo auxílio financeiro às análises isotópicas e editoração da Tese de Doutoramento (Projeto 0772/92). Ao Instituto de Pesquisas Tecnológicas do Estado de São Paulo - IPT pela oportunidade dada ao primeiro autor deste trabalho em realizar o doutoramento. Ao Prof. Dr. Colombo C. G. Tassinari, do Instituto de Geociências da Universidade de São Paulo, pelo empenho na obtenção de dados geocronológicos e auxílio na interpretação de parte destas informações. 


\section{Referências}

Badhan, J. P. N. 1981. The origins of ore deposit in sedimentary rocks. In: TAIRLING, D. H. ed. Economic Geology and Geotectonics. Oxford, Blackwell Scientific " Publication, p. 156-191.

Barbosa, 0. 1941. Geologia e petrologia na região de Apiaí, Estado de São Paulo. São Paulo. 76 p. (USP, Escola Politécnica. Tese de Doutoramento).

Batchelor, R. A. \& Bowden, P. 1985. Petrogenetic interpretation of granitic rock series using multicationic parameters. Chem. Geol., 48: 43-55.

Bettencourt, J. S.; Daitx, E. C: Moreira, M. Z.- Matsui, E. M. 1990. EstudoIsotópicopelos métodos ${ }^{13} \mathrm{C}^{12} \mathrm{C}^{18}{ }^{18} \mathrm{O} /{ }^{16} \mathrm{O}, \quad \mathrm{De}^{34} \mathrm{Sr}^{32} \mathrm{~S}$ dos depósitos de chumbo-zinco-prata do Vale do Ribeira. Estados de São Paulo e Paraná. São Paulo. 45 p. (FAPESP. Relatório de Projeto de Pesquisa).

Brown, P. E.; Bowman. J. R.; Kelly, W. C. 1985. Petrology and Stable Isotope Constraints on the Source and Evolution of Skarn-Forming Fluids at Pine Creek, California. Econ. Geol., 80: 72-95.

Campanha, G. da C. 1991. Tectônica proterozóica no alto e médio Vale do Ribeira, estados de São Paulo e Paraná. São Paulo. 2v. (USP, Instituto de Geociências. Tese de Doutoramento).

Campanha, G. A. da C.; Bistrichi, C. A.; Almeida, M. A. 1987. Considerações sobre a organização litoestratigráfica e evolução tetônica da Faixa de Dobramentos Apiaí. In: Simpósio Sul-Brasileiro de Geologia, 3. Curitiba, 1987. Atas... Curitiba, SBG. v. 2 , p. $725-742$

Campanha, G. A. da C.; Gimenez Filho, A.; Sadowski, G. R. 1994. Tectônica da Faixa Ribeira. In: Congresso Brasileiro de Geologia, 38. Florianópolis, 1994. Boletim de Resumos Expandidos... Florianópolis, SBG. v.1, p. 271-272.

Campanha, G. A. da C.; Gimenez Filho, A.; Caetano, S. L. V.; Pires, F. A.; Dantas, A. S. L.; Teixeira, A. L.; Dehira, L. K. 1986. Geologia e estratigrafia da região das folha Iporanga e Gruta do Diabo, Vale do Ribeira, São Paulo. In: Congresso Brasileiro de Geologia, 34. Goiânia, 1986. Anais... Goiânia, SBG. v.2, p. 1058-1073.

Campanha, G. da C.; Machado Júnior, D. de L.; Nagata, N.; Dantas, A. S. L.; Ens, H. H.; Gimenez Filho, A.; Bistrichi, C. A.; Ferreira, F. J.; Monma, R.; Echebehere, M. L. de C.; Rondinelli, D.; Stein, D. P.; Maeyama, O.; Dehira, L. K.; Bordignon, J. L. 19\&8. Avaliação preliminar da geologia da Folhas (em 1:50000), Taquaral, Mina do Espírito Santo, Ribeirão Itacolomi, Serra do Aboboral, Jacupiranga (Eldorado Paulista), Rio Guaraú (Barra do Azeite), Rio Turvo (Serra do Aleixo), Vale do Ribeira, SP. São Paulo. 4v. (IPT. Relatório, 26863 ).

Chiodi filho, C. Santos, J. F.; Soares, P. C.; Moretzsohn, J. S. 1989. Estudo de elementos terras-raras para caracterização e avaliação metalogenética de granitóides no escudo paranaense. In: Congresso Brasileiro de Geoquímica, 2. Rio de Janeiro, 1989 Anais... Rio de Janeiro, SBG. p. 487-498.

Daitx, E. C.; Teixeira, W.; Zanardo, A. 1990. Geologia e geocronologia do metagabro de Apiaí, Vale do Ribeira, São Paulo. In: Congresso Brasileiro de Geologia, 36. Natal, 1990. Boi. Rés ... Natal, SBG. p. 341.

Deines, P. \& Gold, D. P. 1969. The change in $\mathrm{C}$ and $\mathrm{O}$ isotopic compositions during contact metamorphism of the Trenton Limestone by the Mount Royal pluton. Geochim. Cosmochim. Acta, 33:421-424

Didier, J. 1987. Contribution of enclave studies to the understanding of origin and evolution of granitic magmas. Geolog. Rundsch., 76:41-50.

Eert, M. 1971. Observações sobre a litologia e subdivisão do "Grupo Setuva" no Estado do Parana, com sugestões à tetônica geral do "Geossinclíneo Açungui". In: Congresso Brasileiro de Geologia, 25. São Paulo, 1971. Anais... São Paulo, SBG. p. 131-146.

Ebert, H. D.; Arthur, A. C.; Chemale Júnior, F.; Babinsky, M.; Schmus, W. R. Van. 1994. Regimes tectônicos e idades $\mathrm{U} / \mathrm{Pb}$ em zircão do Complexo Socorro no contexto da Faixa Ribeira: um exemplo de magmatismo compressivo. In: Congresso Brasileiro de Geologia, 38. Florianópolis, 1994. Anais... Florianópolis, SBG. v.l, p. 260-261.

Edwards, A. B. 1954. Textures of ore minerals and their significance. Melbourne, The Australasian Institute of Mining and Mettalurgy. 242 p.

Einaudi, M. T.; Meinert, L. D.; Newberry, R. J. 1981. Skarn deposits. Econ. Geol., 75th Anniversary Volume: $317-391$.

Elliot, J. E. 1982. Model for contact metassomatic tungsten/cooper/gold deposits. In: Caracteristics of mineral deposits ocorrences. Washington. (USGS. Open-file Report, 795)

Ens, H. H. 1990. Petrogênese dos escarnitos de Itaoca-Vale do Ribeira-SP. São Paulo. 172p. (USP, Instituto de Geociências. Dissertação de Mestrado).

Evensen, N. M.; Hamilton, P. J.; O'Nions, R. K. 1978. Rare-earth abundances in chondritic meteorites. Geoch. Cosmoch. Acta, 42:1199-1212.

Faure, G. 1986. Principles of isotope geology. New York, Jonh Willey \& Sons. 589 p.

Fiori, A. P.; Fassbinter, E.; Gois, J. R.; Fumagalli, C. E. 1987. Compartimentação tectônica do Grupo Açungui a norte de Curitiba: In: Simpósio Sul-Brasileiro de Geologia, 3. Curitiba, 1987. Atas ... Curitiba,SBG. v. 1, p. 183-196.

Garlick, D. G. \& Epstein, S. 1967. Oxigen isotopes ratios in coexisting minerals of regionally metamorphosed rocks. Geochim. Cosmochim. Acta, 31:1214-1238.

Gimenez Filho, A. 1993. Evolução do Complexo Granitico Três Córregos, a noroeste de Apiai - SP. São Paulo. 118 p. (USP, Instituto de Geociências. Dissertação de Mestrado).

Gomes, C. B.; Arruda, J. R.; Berenholc, M.; Hypólito, R. 1975a. Geoquímica de maciços graníticos da região do Ribeira. Parte I: elementos principais. An. Acad. Bros. Ci, 47:113-130

Gomes, C. B.; Arruda, J. R.; Berenholc, M.; Hypólito, R. 1975b. Geoquímica de maciços graníticos da região do Ribeira. Parte II; elementos traços. An. Acad. Brás. Ci., 47:459-476.

Hackspacher, P, C. \& Godoy, A. M. 1995. Transtensional/Transpressional Tectonic and Plutonic Rock Emplacement: The Calc- to Alkaline Granites of the Ribeira Belt, Brazil. In: Symposium on Rapakivi Granites and Related Rocks. Belém, 1995. Abstracts ... Belém, IGCP, p. 40-41

Harris, N.B.W.; Pearce, J.A.; Tindle, A.G. 1986. Geochemical characteristics of collision-zone magmatism. In: Coward, M.P. \& Ries, A.C. eds. Collision Tectonics. Geological Society, p. 67-81.(Special Publ., 19).

Hasui, Y.; Carneiro, C. D. R.; Coimbra, A. M. 1975. The Ribeira Folded belt. Rev. Bras. Geoc., 5:254-267.
Hasui, Y.; Carneiro, C. D. R.; Bistrichi, C. A. 1978. Os granitos e granitóides da Região de Dobramentos Sudeste nos Estados de São Paulo e Paraná. In: Congresso Brasileiro de Geologia, 30. Recife, 1978. Anais...Recife, SBG. v.6, p. 2594-2608.

Hasui, Y.; Cremonini, O. A.; Born, H. 1984. Considerações sobre o Grupo Açungui em São Paulo e porções adjacentes do Paraná. In: Congresso Brasileiro de Geologia, 33. Rio de Janeiro, 1987. Anais...Rio de Janeiro, SBG. v.7, p. 3297-3306.

IUGS - International Union of Geological Sciences. 1973. Plutonic rocks classification and nomenclature recomended by the IUGS subcomission on the systematics of igneus rocks. Geotimes, 18:26-30.

Janasi, V. A. \& Ulbrich, H. H. G. J. 1991. Late Proterozoic granitoid magmatism in the state of São Paulo, southeastern Brazil. In: HAAPALA, I. \& CONDIE, K. C. eds., Precambriam Granitoids-Petrogenesis, Geochimistry and Metallogeny. Precambrian Res., 51:351-374

JICA - Japan International Cooperation Agency/Metal Mining Agency of Japan. 1981 Report geological survey of Anta Gorda; phase I. s.l. São Paulo. DNPM.

JICA - Japan International Cooperation Agency/Metal Mining Agency of Japan. 1982 Report geological survey of Anta Gorda; phase 2. s.l. São Paulo. DNPM.

JICA - Japan International Cooperation Agency/Metal Mining Agency of Japan. 1983. Report geological survey of Anta Gorda; phase 3. s.l. São Paulo. DNPM.

Jiuliani, C. 1993. Geologia, petrogênese e aspectos metalogenéticos dos grupos Serra do Itaberaba e São roque na região das serras do Itaberaba e da Pedra Branca, NE da cidade de São Paulo, SP. São Paulo. 694 p. (USP, Instituto de Geociências. Tese de Doutoramento)

Kawashita, K.; Sato, K.; Sonoki, R. 1983. Um sistema de aquisição e processamento de dados "on line" em um espectrômetro de massa do Centro de Pesquisas Geocronológicas (CPGeo-USP). São Paulo. 14 p. (USP, Instituto de Geociências. Relatório Interno)

Kequin, X.; Sun, N.; Dezi, W.; Shouxi, H.; Yingjun, L.; Sshouyan, J. 1984. Petrogenesis of the granitoids and their metallogenetic relations in south china. In: International symposium on geology of granited and their metallogenetic relation. Nanjing, 1982. Proceedings... Nanjing, Science Press, p. 1-31.

Kwak, T. A. P. 1987. W-Sn skarn deposits and related metamorfw skams and granitoids Amsterdan, Elsevier. 451 p. (Developments in Economic Geology, 24).

Kwak, T. A. P. \& White, A. J. R. 1982. Contrasting W-Mo-Cu and W-Sn-F skarn type and related granitoids. Min. Geol., 32:339-351.

Lameyre, J. \& Bowsen, P. 1982. Plutonic rock type series: discrimination of various granitoids series and related rocks. /. Volcanol. Geotherm. Res., 14:169-186.

Landim, P. M. B; Gomes, C. B.; Arruda, J. R.; Fúlfaro, V. J. 1975. Análise de agrupamentos aplicada ao estudo geoquímico do granito Itaoca. In: Congresso Brasileiro de Geologia, 27. Porto Alegre, 1975. Anaw.-.Porto Alegre, SBG. Resumo das Comunicações, p. 269-270.

Layne, G. D.; Longstaffe, F. J.; Spooner, E. T. C. 1991. The JC Skarn Deposit, Southern Yukon Territory: II. A carbon, Oxigen, Hidroxen, and Sulphur Stable Isotope Study. Econ. Geol, 86:48-65.

McCrea, J. M. 1950. The isotopic chemistry of carbonates and a paleotemperature scale. J. Chem. Phys. 18:849.

Melcher, G. C.; Gomes, C. B.; Cordani, U. G.; Bettencourt, J. S.; Damaceno, E. C.; Girardi, V. A. V.; Melfi, A. J. 1973. Geologia e petrologia das rochas metamórficas e graníticas associadas do Vale do Rio Ribeira de Iguape, SP e PR. Rev. Bras. Geol. 3 (2), p. 97-123.

Mello, I. S. de C. 1995. Geologia e aspectos metalogenéticos do Maciço Itaoca, Vale do Ribeira, SP e PR. São Paulo. 168p. (USP, Instituto de Geociências. Tese de Doutoramento).

Mello, I. S. de C. \& Silva, R. B. da. 1984. Mineralizações associadas aos granitóides de Itaoca (SP). In : Congresso Brasileiro de Geologia, 33. Rio de Janeiro, 1984. Anais...Rio de Janeiro, SBG. v.6, p. 3001-3011.

Mello, I. S. de C. \& Bettencourt, J. S. 1992. Geologia e aspectos metalogenéticos do batólito Itaoca, Vale do Ribeira (São Paulo e PR). In: Congresso Brasileiro de Geologia, 37. São Paulo, 1992. Boletim de Resumos Expandidos...São Paulo, SBG. v.2, p. 209

Mello, I. S. de C.; Silva, R. B. da; Goraieb, C. L. 1985. As mineralizações de tungstênio (scheelita) nos granitóides de Itaoca (SP). In: Simpósio Regional de Geologia, 5. São Paulo, 1985. Ato...São Paulo, SBG. v.2,p. 433-444.

Mello, I. S. de C; Silva, J. R. B. da; Boin, M. N.; Saragiotto, A. J. R.; Silva, R. B. da. 1981. Geologia dos granitóides de Itaoca (SP). In: Simpósio Regional de Geologia, 3 Curitiba, 1981. Atas...Curitiba: SBG, v.1, p. 82-93.

Nakano, T.; Shimazaki, H.; Shimizu, M. 1990. Stoncium Isotope Systematics and Metallogenesis of Skarn Deposits in Japan. Econ. Geol., 85:823-844.

Newbrerry, R. J. 1982. Tungsten bearing skarns of the Sierra Nevada. I. The Pine Creek Mine, California. Econ. Geol, 77:823-844

Pearce, J.A.; Harris, N.B.W.; Tindle, A.G. 1984. Trace element discrimination diagrams for the tetonic interpretation of granitic rocks. J. Petrol., 25:956-983.

Pires, F. A. 1990. Análise paleoambiental e estratigráfica de seqüências metassedimentares (Grupo Açungui) na região de Iporanga e Apiai. São Paulo. 151 p. (USP, Instituto de Geociências. Dissertação de Mestrado).

Pitcher, W. S. 1982. Granite type and tectonic environment. In: Hsu, J.K. ed. Moutain Building Process. London, Academic Press, p. 19-40.

Pitcher, W. S. 1987. Granite and yet more granites forty years on. Geolog. Rundsch., 76:51-79.

Plant, J.A.; Simpson, P. R.; Green, P. M.; Watson, J. V.; Fowller, M. B. 1983. Metalliferous and mineralized Caledonian granites in relation to regional metamorphism and fracture in northern Scotland. Trans. Inst. Min. Metall., 92:33-42.

Ponçano. W. L.;Carneiro, C. D. R.; Bistrichi, L. A.; Almeida, F. F. M. de; Prandini, F. L. 1981. Mapa Geomorfológico do Estado de São Paulo. São Paulo. IPT/PRÓ-MINÉRIO. 2v.

Poidevin, J. L.; Viallete, Y.; Reis Neto, J. M. dos. 1997. Radiometric ages (Pb-Pb) of the Ribeira belt calcareous rocks. In: South-american Symposium on Isotope Geology, Campos do Jordão, 1997. Extented Abstracts ... Campos do Jordão, IG-USP. p. 242-243.

Raguin, E. 1976. Géologie du Granite. Paris, Masson. 276 p. 
Ramsay, J. G. 1981. Emplacement mechanics of the Chindamora Batholith, Zimbabue. In: Coward, M. P. ed. Diapirism and Gravity Tectonics: Report of a Tectonic Group Studies Conference at Leeds University. Struct. Geol, 3:93.

Ruiz, J; Jones, L. M.; Kelly, W. C. 1984. Rubidium-Strontium dating of ores deposits hosted by $\mathrm{Rb}$ rich rocks using calcite and other common $\mathrm{Sr}$ bearing minerals. Geology, 12:259-263.

Sato, K.; Tassinari, C. C. G.; Kawashita, K; PetroniHio, L. 1995. Método geocronológico Sm/Nd no IG-USP e suas aplicações. An. Acad. Bras. CL, 67:313-336.

Smirnov, V. 1.1982. Geologia de jacimentos minerales. Moscow, Ed. Mir. 654p.

Soares, P. C. 1987. Seqüências tectono-sedimentares e tetônica deformadora no centro-oeste do escudo paranaense. In: SIMP. SUL-BRAS. GEOL., 3. Curitiba, 1987. Afaj...Curitiba, SBG. v.2, p. 743-771.

Soares, P. C. 1988. Tectônica colisional em torno do Bloco Paraná, Brasil. In: Congresso Latino-americano de Geologia, 7. Belém, 1988. Anais...Belém, SBG. v. 1, p. 63-79.

Stacey, J. S. \& Kramers, J. D. 1975. Approximation of lead isotope evolution by a two stage model. Earth Planet Sci. Let., 26:207-221.

Steiger, R. H. \& Jaeger, E. 1978. Subcomission on geochronology: convention on the use of decay constante in geochronology and cosmochronology. Contributions to the geologic time scale. In: Studies in Geology. Michigan. 1:67-72.

Tassinari, C. C. G.; Mello, I. S. de C. 1994. A idade e a origem das mineralizações do granitóde de Itaoca. In: CONG. BRAS. GEOL., 38. Florianópolis, 1994. Boletim de Resumos Expandidos...SÃo Paulo, SBG. v.J, p, 304-305.

Tassinari, C. C. G ; Mello, I. S. de C.; Gomes, D. P. 1994. Sr and Pb isotope evidence for the on gen of skarn, sulfides and fluor mineralizations of the Itaoca granitoid, southern Brazil. In: International Conference on Geochronology, Cosmochronology and Isotope Geology, 8. Berkeley, 1994. Abstracts... Berkeley, USGS. p. 316.

Tassinari, C. C. G.; Barbour, A- P.; Daitx, E. C.; Sato. K. 1990. Aplicação dos isótopos de $\mathrm{Pb}$ e Sr na determinação da natureza das fontes das mineralizações de chumbo do Vale do Ribeira - SP e PR. In: Congresso Brasileiro de Geologia, 36. Natal, 1990. Anais... Natal, SBG. v.3, p.1254-1266.

Taylor Junior, H. P. \& Epstein, S. 1962. Relationship between ${ }^{18} 0 /$ O ratios in coexisting minerals of igneous and metamorphic rocks. Part I: Principles and experimental results. Part II: Application to petrological problems. Geol. Soc. America Bull., 73:461-480/675-694
Torquato, J. R. 1974. Geologia do sw de Moçamedes e suas relações com a evolução tetônica de Angola. São Paulo. 243p. (USP, Instituto de Geociências. Tese de Doutoramento)

Valley, J. W.; Taylor Junior, H. P.; O'Neil, J. R. 1986. Stable Isotope Geochimistry of metamophic rocks. Revs. Mineralogy, 16:445-489.

Veizer J. \&Hoefs, J. 1976. The nature of ${ }^{18} \mathrm{O} /{ }^{16} 0$ and ${ }^{13} \mathrm{C} /{ }^{12} \mathrm{C}$ secular trends in sedimentary carbonate rocks. Geoch. Cosmoch. Acta, 40:1387-1395.

Wernick, E. 1979. Aspectos petrológicos dos granitóides da Província Ribeira, SP e PR. In: Simpósio Regional de Geologia, 2. Rio Claro, 1979. Anaw...Rio Claro, SBG. v.1.p. 101-116.

Wernick, E. 1990. Zoneamento magmático regional dos granitóides brasilianos no Sudeste/Sul do Brasil: implicações geotectônicas. In: Congresso Brasileiro de Geologia, 36. Belém, 1990. y4naw...Belém: SBG. v.4, p. 1668-1683.

Wernick, E. \& Gomes, C. B. 1974. Granitos e metamorfismo no vale do rio Ribeira de Iguape, SP e PR. In: ngresso Brasileiro de Geologia, 28. Porto Alegre. Anais...Pono Alegre: SBG. v.5,p.!45-154.

Wernick, E. \& Gomes, C. B. 1977. Geoquímica de Maciços Graníticos da Região do Ribeira. Parte HI: Considerações Petrológicas. An. Acad. Bros. CL, 49:157-169.

Williamson, J. H. 1968. Least square fitting of a straight line. Can. Jour. Physics., 46:1845-1847.

Winkler, H. G. F. 1977. Petrogênese das rochas metamórficas. São Paulo, Edgard Blücher. $254 \mathrm{p}$.

Zartman, R. E. \& Doe, B. R. 1981. Plumbotectonics-The model. Tectonophysics, 75:135-162.
MANUSCRITO A-940

Recebido em 15 de outubro de 1997 Revisão dos autores em 20 de fevereiro de 1998-03-05 Revisão aceita em 25 de fevereiro de 1998 